\title{
24
}

\section{Radiant Tube Burners}

\author{
Michael Flamme, Ambrogio Milani, Joachim G. Wünning, Wlodzimierz Blasiak, \\ Weihong Yang, Dariusz Szewczyk, Jun Sudo, and Susumu Mochida
}

\section{CONTENTS}

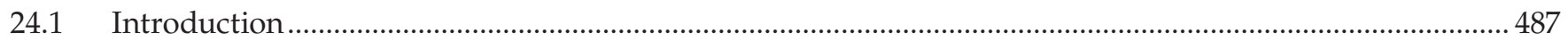

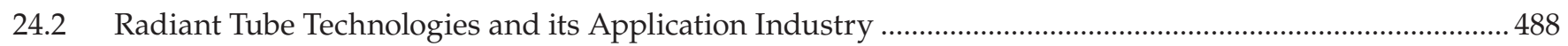

24.3 Important Quality Characteristics of Radiant Tubes ................................................................................ 492

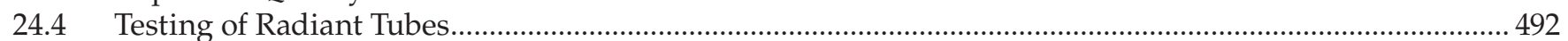

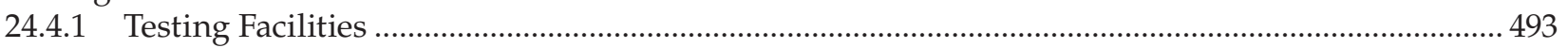

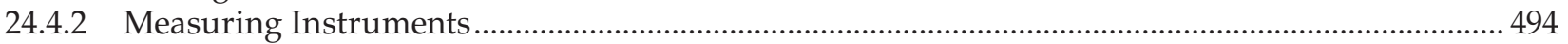

24.5 Comparative Performance Data Between Regenerative and Recuperative Radiant Tube Burners.............. 494

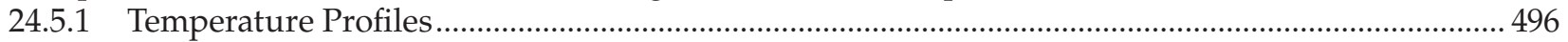

24.5.2 Effective Energy from the Radiant Tube........................................................................................... 497

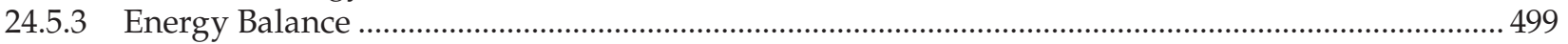

24.5.4 Emissions and Pressure Drop …………...........................................................................................50

24.5.5 Conclusions from the Measurements with Different Burners ……….............................................500

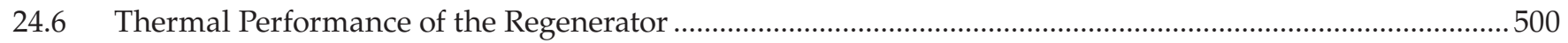

24.7 Estimation of Mechanical Strength of the Radiant Tube .............................................................................50

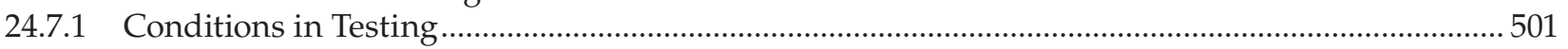

27.7.2 Temperature Profile along the Tube Length and the Tube Circumference ....................................... 501

24.7.3 Numerical Analysis of the Thermal Stress of the Radiant Tube ....................................................... 501

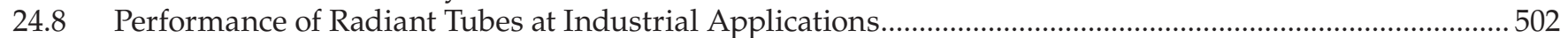

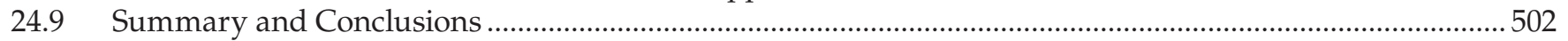

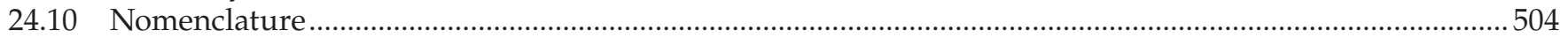

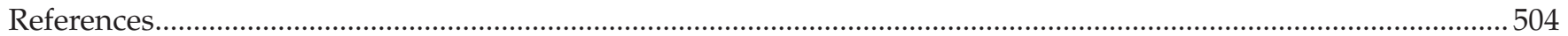

\subsection{Introduction}

Radiant tubes are used in industry for heat treatment applications in which products are treated under a protective gas atmosphere within heat treatment furnaces. Therefore the heating of such furnaces are performed with indirect fuel-fired systems or electrical heating elements. For indirect fired applications, the flue gas of the combustion process can not enter into the furnace. The combustion takes place within radiant tubes and the heat is transferred-via radiation-from the outer surface of the tube to the process. There are different types of radiant tubes available. For all types the maximum transferred heat is one of the important features of such systems. That means that the maximum radiant tube temperature and the temperature uniformity are important characteristics of radiant tubes. Another issue is the efficiency of the radiant tubes. In all types of radiant tubes the combustion takes place within the tube and the flue gas leaves the tube at the flue gas outlet. The efficiency of radiant tubes depends on the flue gas outlet temperature. The lower the flue gas temperature the higher is the efficiency of a combustion system. That means as much as possible of the provided energy must be transferred via the radiant tubes to the process and the flue gas outlet temperature must be as low as possible. One way of reducing the flue gas losses is heat recovery from the flue gas for preheating the combustion air. Therefore radiant tubes with internal air preheating technologies like plug-in recuperators, recuperative and regenerative burners have been developed.

Another important characteristic of radiant tubes is pollutant emission like $\mathrm{NO}_{x}$ and CO. It is important to implement state of the art combustion technology into radiant tubes in order to keep the emissions as low as possible. The lifetime of radiant tubes and maintenance 
costs are also important for the economical application of the technology in heat treatment applications.

Experimental investigations of radiant tubes in laboratory furnaces and under practical conditions in field tests are important in order to develop and improve radiant tubes. This chapter will give an overview about the different radiant tube technologies and its application in industry and will describe measurement techniques for experimental investigations of radiant tubes in laboratory furnaces.

\subsection{Radiant Tube Technologies and its Application Industry}

Radiant tubes are used in industry for different heat treatment processes with a protective gas atmosphere in steel and nonferrous metal industry. Radiant tubes are fueled with natural gas, LPG, or light fuel oil. Process heating with radiant tubes leads to lower energy costs compared to electrical heating systems. There are different radiant tubes with different geometries, burners, air preheating technologies, and materials on the market. Radiant tubes can be classified by different criteria. One of the important criteria for the distinction of different systems is if the geometry of the radiant tube allows an internal flue gas recirculation within tube [1]. The internal flue gas recirculation within the radiant tube leads to a better temperature uniformity at the surface of the radiant tube and leads in conjunction with high velocity burners to a recirculation of combustion products into the reaction zone. As a result of the flue gas entrainment the reaction zone will be diluted. Due to the dilution, the flame temperature and the partial oxygen pressure within the reaction zone will be reduced simultaneously. As a consequence the thermal NO formation will be reduced drastically. The dilution of the reaction zone with flue gas leads to a nonvisible flame because the local concentration of $\mathrm{OH}, \mathrm{CH}$, and other intermediate products will be reduced and called flameless combustion. The diluted combustion technology is mostly used in conjunction with preheating of the combustion air. Flameless technologies are also described in Chapters 21 and 23 of this book. They are often used in conjunction with high preheating of the combustion air, because they are required to abate $\mathrm{NO}_{\mathrm{x}}$ emissions and to curb temperature peaks.

Figure 24.1 gives an overview about the different types of radiant tubes $[4,5]$. On the left side of the figure, nonflue gas recirculating radiant tubes are shown. The simplest design is the I-type radiant tube with a burner on one side and the flue gas outlet at the opposite side. This type of radiant tube will be found in Europe only in old installations. The reason for that is the mostly unused combustion air preheating, difficulties with sealing of the moving part of the radiant tube due to thermal distension, the insufficient temperature uniformity at the surface of the radiant tube, and the high flue gas temperatures at the flue gas outlet of the tube.

For an enlargement of the surface, I-type radiant tubes can be extended with bends and additional arms in order to build U-type and W-type radiant tubes. With these extensions, the radiation surface of the tubes can be enlarged. For I-type, U-type, and W-type radiant tubes the burners are placed at one end and the flue gas outlet is at the other end. At a one-sided, sealed radiant tube without recirculation, an inner tube will be implemented into an I-type tube and the opposite end will be blocked. The burner will be implemented into the inner tube and the flue gas goes first through the inner tube and flows back in the annulus between the inner tube and radiant tube. Nonrecirculating radiant tubes like the U-type and W-type tubes are mostly used in the American market.

In the European market single ended radiant tubes (SER) in combination with auto recuperative burners are the most used types. Single-ended radiant tubes are recirculating types of radiant tubes because there is an annular gap between the burner and the inner tube for flue gas recirculation. Single-ended radiant tubes offer excellent temperature uniformity and they are easy to install into a furnace because they have just one flange and one sealing with the furnace wall at the cold end of the radiant tube. The other end can expand within the furnace due to thermal distension. Horizontally installed steel radiant tubes need an end support at the opposite side of the burner within the furnace. Singleended radiant tubes have, with their inner tubes, one additional part compared to other types of radiant tubes. Other radiant tubes with internal flue gas recirculation are the P-type, double P-type, and A-type radiant tubes. For these tubes the possibility for internal flue gas recirculation is based on the design of the tubes.

A uniform temperature distribution is important in order to achieve a uniform heating up of the product within the heat treatment furnace, a maximum heat flux from the tube to the process, and a long life span of the radiant tubes. For nonrecirculating radiant tubes, slowly mixing burners with long flames will be used so that the flame covers the first part of the radiant tube. Overheating of the part of the radiant tube close to the burner could be the result of too short flames. Too long flames lead to overheating problems due to turbulences that occur in the first bend of the radiant tube and the completing of the combustion within this part. In conjunction with modulating temperature control, it is difficult to achieve these targets at different loads of the burners. With recirculating radiant tubes, high velocity burners in on/off 

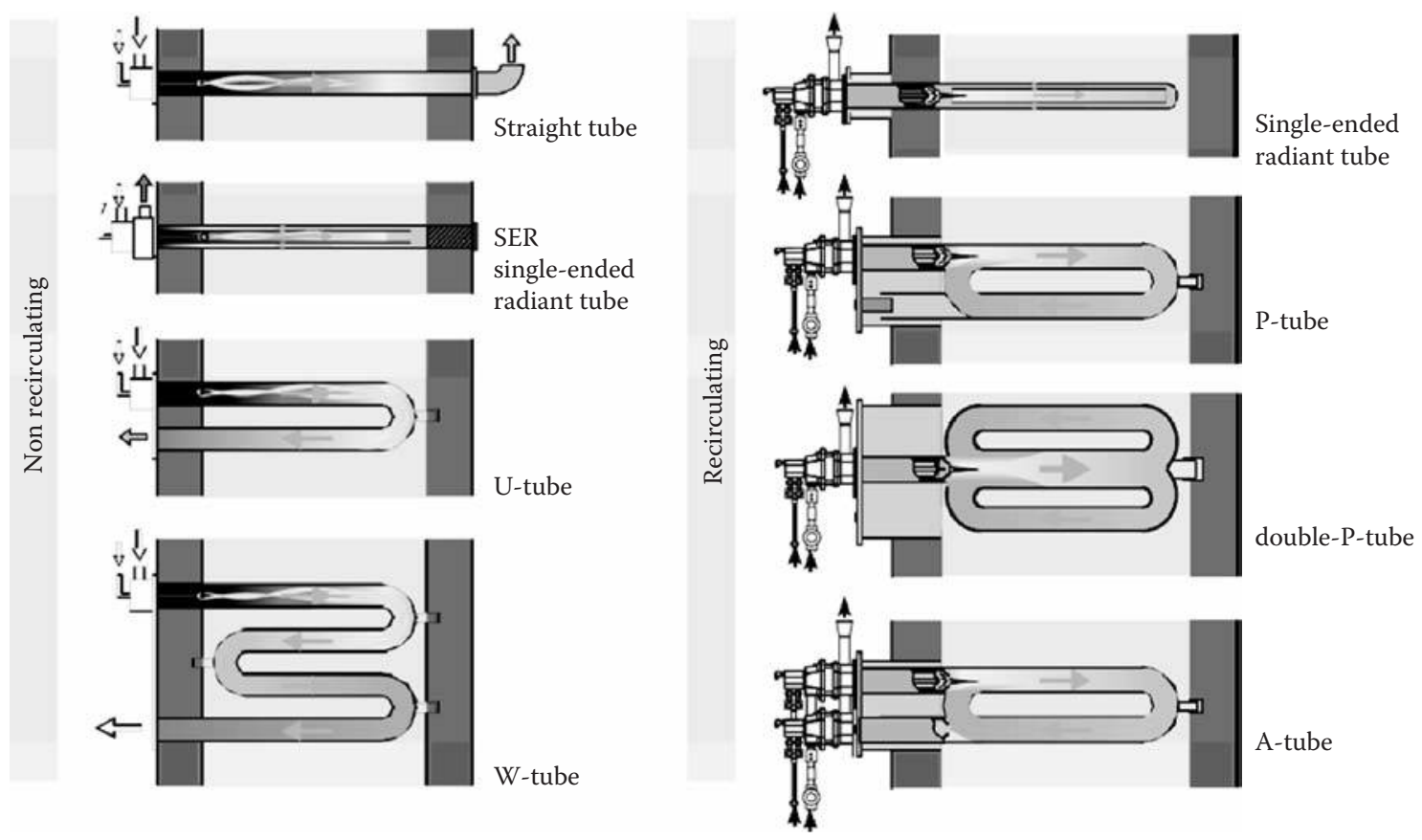

FIGURE 24.1

Different types of radiant tubes with non flue gas recirculation (left) and flue gas recirculation (right).

operation will be used. The temperature uniformity will be achieved through the intensive flue gas recirculation within the inner part of the radiant tubes. Temperature differences at the surface of the radiant tubes are lower at recirculating tubes compared to nonrecirculating tubes. Figure 24.2 shows the maximum temperature distribution at the surface of different radiant tube technologies [2]. The temperature difference is in the range of $130-150 \mathrm{~K}$ for U- and W-shaped radiant tubes and drops down to the range of $20-50 \mathrm{~K}$ for single-ended and P-shaped radiant tubes. Single-ended radiant tubes are the ideal geometry in order to achieve a uniform temperature distribution. If the temperature distribution is not uniform, the part of the radiant tube that has a lower temperature has a reduced contribution to the total heat transfer compared to the part that has the maximum surface temperature. This results in a reduction of the total heat, which can be transferred by the radiant tubes. The penalty for this effect leads to an assumed reduction in heat transfer surface of the radiant tube compared to the heat transfer surface at maximum temperature. As a result the investment costs in the heat transfer surface of radiant tubes and in the furnace length could be reduced with radiant tubes designs, which lead to an excellent temperature uniformity.

Most of the radiant tubes are made of heat resistant cast alloy or fabricated alloy. The maximum furnace temperature for heat treatment processes is in the range of $900-1100^{\circ} \mathrm{C}$ depending on the type of material the radiant tubes are made of. Higher temperatures can be achieved with special alloy or ceramic tubes in conjunction with ceramic auto recuperative burners. Ceramic radiant tubes and parts of ceramic auto recuperative burners are made of reaction bound silicon carbide (SiSiC).

Ceramic radiant tubes have been on the market since the mid-1990s. The heat transferred from the radiant tubes to the furnace is a limitation in production capacity of a furnace. With ceramic radiant tubes, the production rate of a furnace can be largely increased due to the higher surface temperature and the higher heat flux of the radiant tubes. The resistance of the silicon carbide material is so high that ceramic radiant tubes can be implemented into a furnace without end support at furnace temperatures of up to $1250^{\circ} \mathrm{C}$ [3]. The $\mathrm{SiSiC}$ is resistant against most of the components of the furnace atmosphere without the alkaline metals potassium and sodium, which can cause corrosion even at low temperatures like $1000^{\circ} \mathrm{C}$. Potassium and sodium are often components of washing agents and can be transported into the furnace together with materials that are brought into the furnace for heat treatment if they are not cleaned carefully after washing. Additionally silicon carbide tubes can be affected in dry hydrogen atmospheres [1].

The efficiency of a fuel-fired system is basically the thermal efficiency or also called available heat. The thermal efficiency of a combustion system is depending on the energy that is transported into the system by fuel input minus the thermal energy that is leaving the system at the flue gas outlet. In order to increase 
W- Rohr

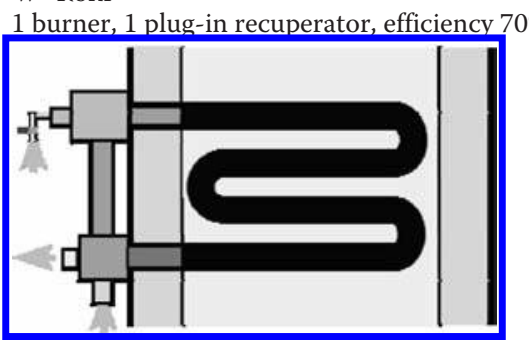

U- Rohr

2 burner; 2 plug-in recuperator, efficiency $70 \%$

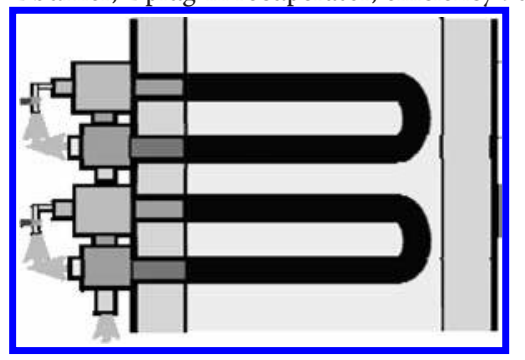

P- Rohr

2 Rekumat SI2 efficiency $78 \%$

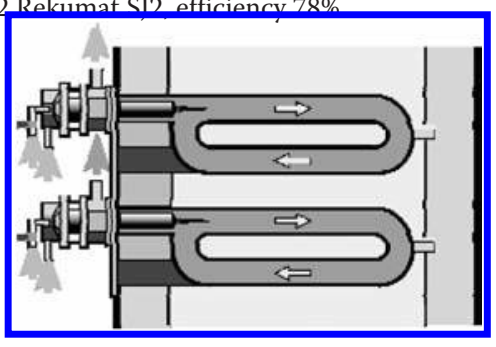

Doppel - P - Rohr

1 Rekumat SJ3, efficiency 78\%

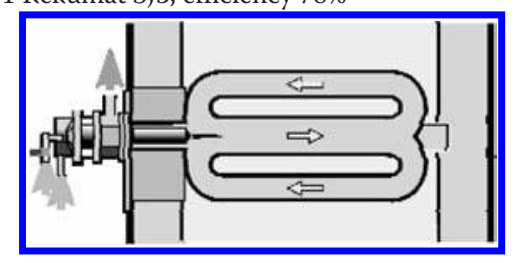

Mantelstrahlrohr

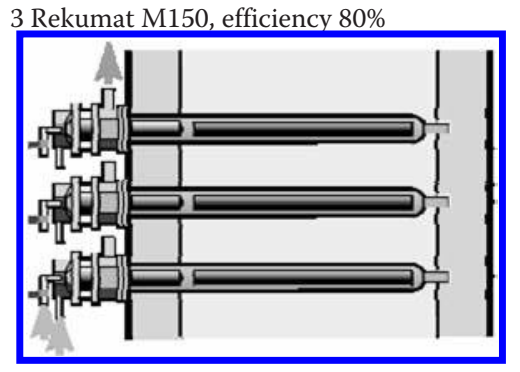

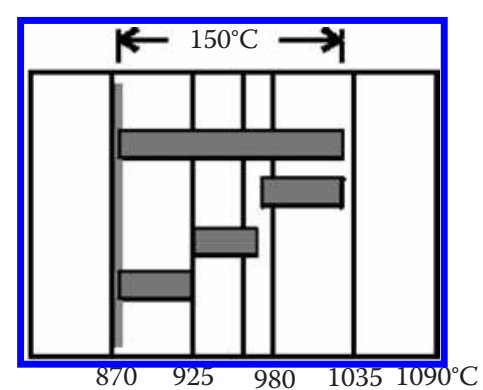
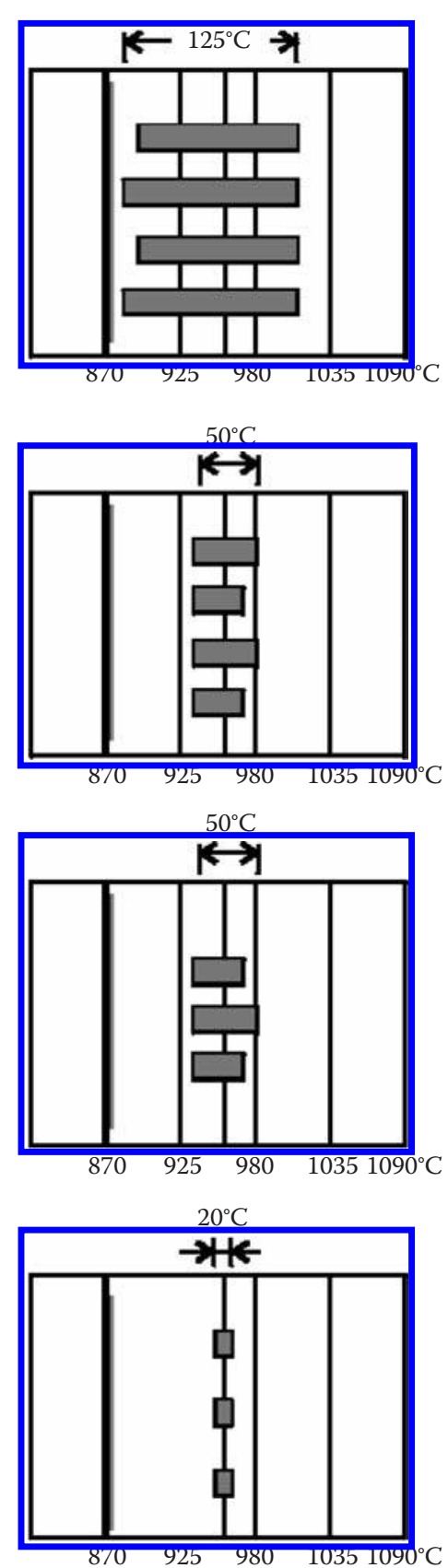

FIGURE 24.2

Effect of inner recirculation on temperature distribution at the surface of the radiant tubes. 
the efficiency, the flue gas outlet temperature must be as low as possible. One effective way is preheating the combustion air by heat recovery from flue gas. In order to increase the efficiency from radiant tubes, plug in recuperators, recuperative, or regenerative burners will be used at radiant tubes to use the energy from flue gas for preheating the combustion air. For U-type and W-type radiant tubes, plug-in recuperators can be used to improve the thermal efficiency. Figure 24.3 shows the application of plug-in recuperators at a U-shaped radiant tube. Another possibility for air preheating at A-, $\mathrm{U}$-, or W-type radiant tubes is the implementation of a regenerative burner pair at such tubes. For this type of radiant tubes one regenerative burner will be installed at each end of the tube. Figure 24.4 shows an installation of regenerative burners at a $\mathrm{W}$-type radiant tube.

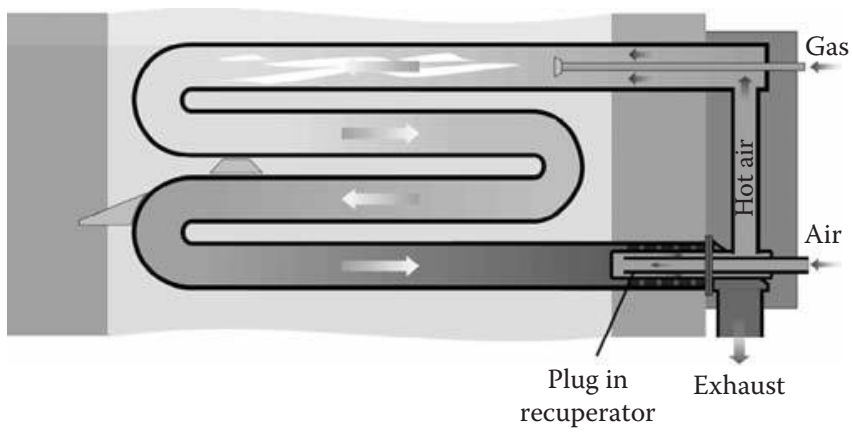

FIGURE 24.3

$\mathrm{W}$-type radiant tube with plug in recuperator.
In Japan, regenerative burners are applied in U-, W-, and I-type radiant tubes with different kinds of fuels like natural gas, propane, butane, coke oven gas, and process gas [10,11]. In the state of the art regenerative combustion system, the major advantages are ultimate heat recovery rate due to the regenerator, uniformity of temperature profile in the furnaces or inside the radiant tubes, and low $\mathrm{NO}_{x}$ capabilities on the basis of High Temperature Air Combustion or HiTAC technology. In $\mathrm{U}-, \mathrm{W}-$, and I-type regenerative radiant tube burner systems two identical regenerative burners are installed in each end of the radiant tube.

For single-ended, P-shaped, and double P-shaped radiant tubes recuperative burners can be used. Figure 24.5 shows the application of a recuperative burner in a SER tube. There are also regenerative burners on

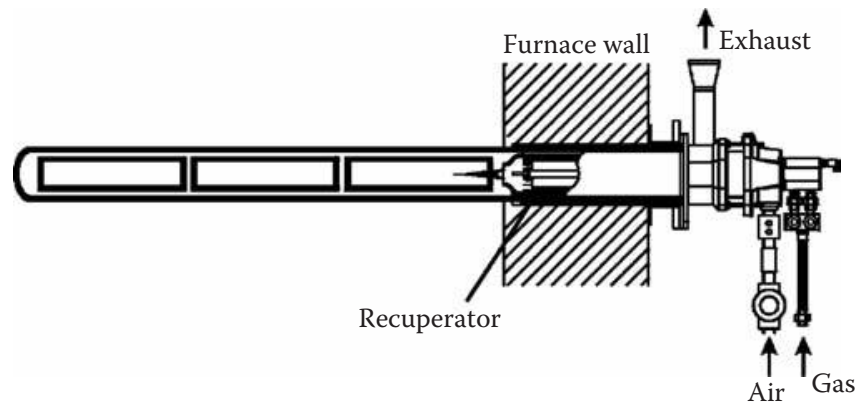

FIGURE 24.5

Application of a recuperative burner in a single-ended radiant tube.
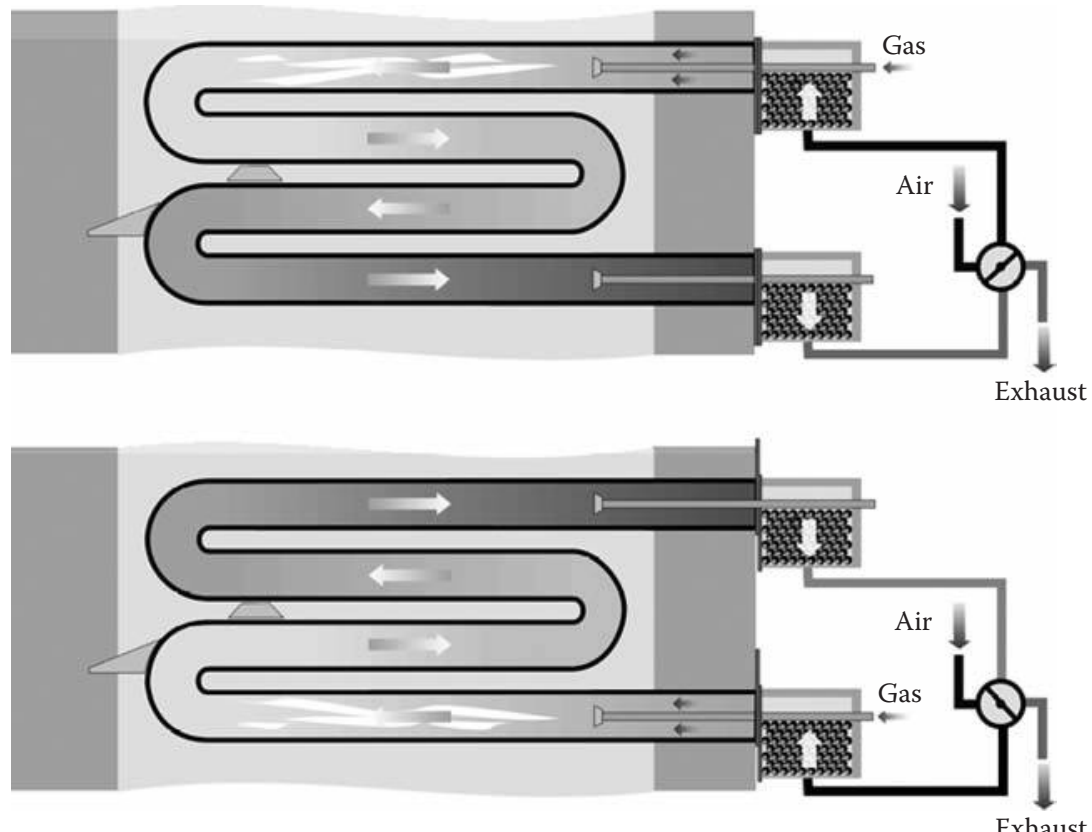

FIGURE 24.4

W-type radiant tube with regenerative burners. 


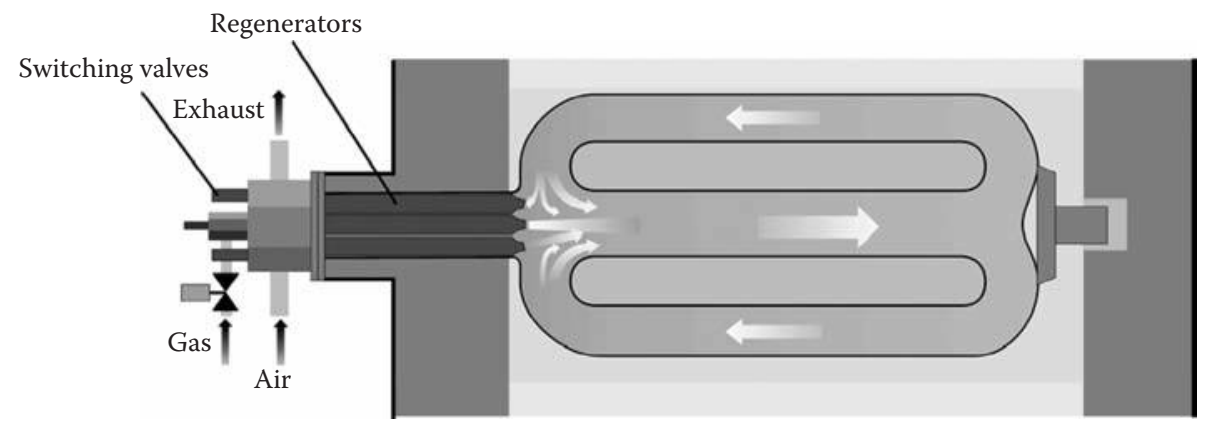

FIGURE 24.6

Application of a regenerative burner in a double P-shaped radiant tube.

the market that integrate a regenerative burner pair in one unit, for example, the Regemat ${ }^{\circledR}$ burner from the WS Thermal Process Technology, Inc. This burner has been applied at double P-type radiant tubes [5]. Figure 24.6 shows a double P-shaped radiant tube with regenerative burner.

\subsection{Important Quality Characteristics of Radiant Tubes}

One of the most important quality characteristics of radiant tubes is the maximum heat flux from the tubes to the process/product, the temperature uniformity at the surface of the radiant tubes, and the heat flux uniformity versus the length of the radiant tubes. As discussed previously, the temperature uniformity has a strong influence on the maximum heat that can be transferred from the surface of the tube to the product. Additionally the temperature uniformity also has an influence on the life span of the radiant tube. If there are hot spots at the surface of the tube, thermal corrosion and thermal tension of the material will increase at the hot spots and lead to a reduced life span of the system. Additionally the maximum temperature within the hot spot is limited by the material characteristics of the radiant tube and therefore regions with lower temperatures reduce the total heat, which can be transferred from the radiant tubes.

Another very important quality characteristic is the combustion efficiency (fuel efficiency) of radiant tubes. The efficiency strongly depends on the flue gas outlet temperature of radiant tube systems. In order to achieve maximum efficiency, air preheating systems use the enthalpy of the flue gas for preheating the combustion air simultaneously reducing the flue gas outlet temperature of such systems. High efficiencies with less flue gas losses result in lower fuel consumptions and lead to a reduction of the $\mathrm{CO}_{2}$ emission per ton of product.
Hazardous emissions like $\mathrm{NO}_{x}$, and unburned or partially burned gases like $\mathrm{CO}$ should also be as low as possible. In order to achieve the target and to keep the emission limits of the legislations of the local authority, modern combustion technologies like flameless combustion or HiTAC technologies have to be implemented into the radiant tube system. With standard combustion technologies in combinations with high air preheating, the $\mathrm{NO}_{\mathrm{x}}$ emissions would increase exponentially. So it is important to use internal flue gas recirculation technologies in order to dilute the combustion zone with flue gas. This is even more important for radiant tubes because the gas temperature inside the radiant tube is higher than the equivalent temperature in free flame (direct heating) conditions. This is inevitable because of the screening effect of the tube wall that hinders direct heat transfer from the flame to the stock.

The pressure drop over radiant tube systems including burner and air preheating technology is also an important factor because higher pressure drop costs more electrical power for the air van and has to be taken into account for total efficiency calculations.

Other important quality characteristics are required in maintenance and the life span of radiant tube systems. Therefore in experimental investigations, long time experiments will also be necessary in order to get information about these characteristics.

\subsection{Testing of Radiant Tubes}

In order to get information about the quality characteristics of radiant tubes experimental investigations are necessary. With computational fluid dynamic (CFD) simulations, an optimization of combustion systems is possible but finally the combustion systems have to be tested experimentally. With experimental work it is possible to get results from existing radiant tubes or to develop new technologies. The tests can be carried out 
in lab-scale furnaces with high temperature conditions and also in industrial applications under practical conditions. But in industrial applications it is not easy to carry out experiments without any disturbance of the production. Therefore most of the tests will be carried out at lab-scale furnaces. In lab-scale furnaces, experiments can be carried out with industrial scale radiant tubes because the thermal load of the radiant tubes is not too high for lab-scale conditions. The thermal load of radiant tubes for industrial applications is in general less than $300 \mathrm{~kW}$ per tube. In order to get information about the temperature uniformity at the surface of the radiant tube, the maximum heat flux measurements of the temperature distribution along the radiant tube surfaces have to be carried out. Additionally results of the efficiency, the $\mathrm{NO}_{x}$ and $\mathrm{CO}$ emissions and the maintenance and lifetime of the radiant tubes can be achieved at lab-scale furnaces. It is also possible to test the influence of different burner technologies on the performance characteristics of radiant tubes at lab-scale furnaces. For these tests radiant tubes can be equipped with different burner technologies in order to estimate the influence of the performance of the radiant tubes. Under practical conditions in industrial applications, it is possible to carry out measurements of the emissions and the efficiency (flue gas outlet temperature and excess air ratio) and to get information about the effort for maintenance and the lifetime of radiant tube systems. In special cases it could be possible to change just one radiant tube of an industrial furnace in order to test it under production conditions.

\subsubsection{Testing Facilities}

In order to test radiant tubes the systems have to be tested in lab-scale furnaces in which one can achieve similar conditions like in industrial applications concerning process temperature, surface temperature of the radiant tubes, and heat flux. Therefore a lab-scale furnace should be equipped with a heat sink in order to control the furnace temperature. For measurements of the efficiency and the emissions like $\mathrm{NO}_{\mathrm{x}}$ it is also important to test the radiant tubes at the same conditions like in the industrial applications because the temperature of the radiant tube has an influence on the results. Also tests to get information about the effort for maintenance and life span of the radiant tubes during a longer testing period can be carried out in the same conditions as the industrial application. In the following some lab-scale furnaces for testing radiant tube systems are shown.

Figure 24.7 shows the semi-industrial HiTAC test furnace of the Royal Institute of Technology (KTH), Stockholm, Sweden. The outer dimensions of the furnace body is $3.500 \times 2.200 \times 2.200 \mathrm{~m}$. The furnace body

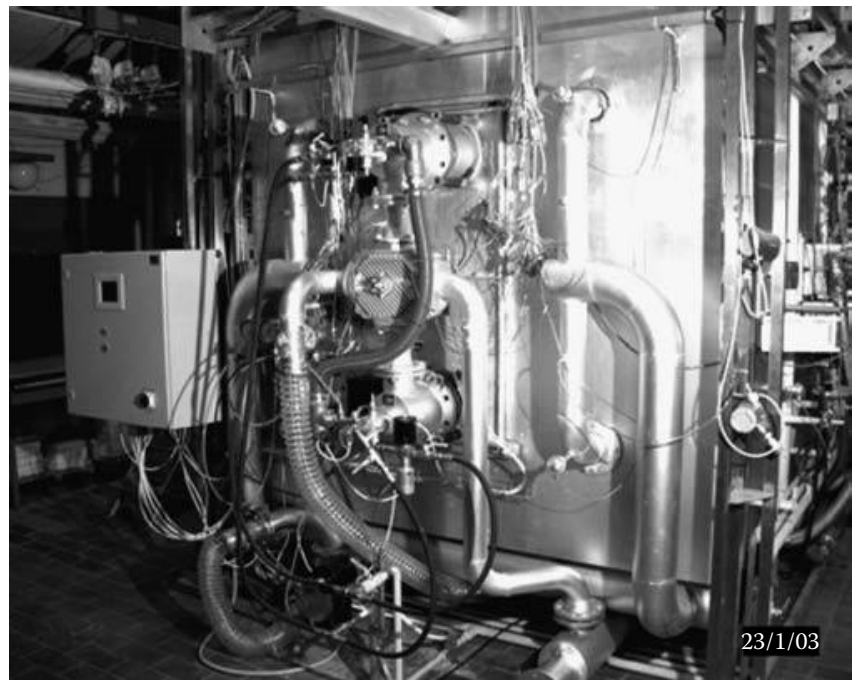

FIGURE 24.7

Front side of the furnace equipped with high-cycle regenerative system.

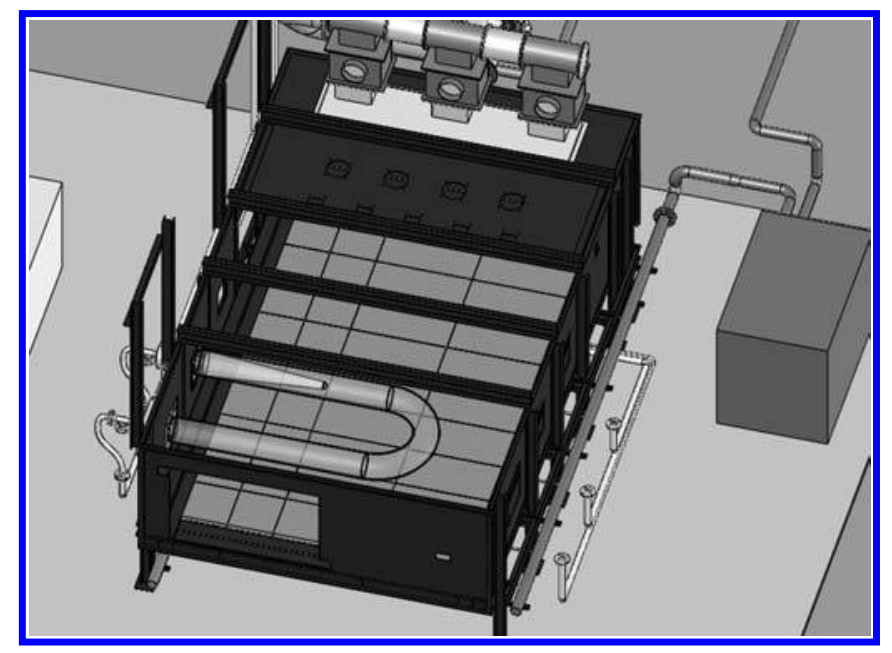

FIGURE 24.8

(See color insert following page 424.) Furnace layout for testing of radiant tube performance in pilot-scale industrial furnace.

is insulated with a $0.3 \mathrm{~m}$ thick layer of ceramic fiber material. The inner volume of the combustion chamber is $7.4 \mathrm{~m}^{3}$ [7].

Figure 24.8 shows the layout for testing radiant tube performance in a pilot-scale industrial furnace (PSIF) of the Canmet Energy Technology Centre, Ottawa, Ontario, Canada [9]. The furnace is $4.5 \mathrm{~m} \times 3.0 \mathrm{~m} \times 1.0$ $\mathrm{m}$ (inside dimensions) and it can be modified to simulate any industrial furnace geometry. With a firing rate of 1.2 MW, the temperature, heat transfer, and chemical environment found in most industrial processes can be emulated as well. The furnace is equipped with a calorimeter for total heat flux (34 cooled plates on the floor of furnace). 


\subsubsection{Measuring Instruments}

For testing the temperature uniformity, thermocouples have to be positioned at the surface of the radiant tubes in order to get information about the surface temperature distribution along the axis of the tubes. For testing the heat flux, total heat flux probes or narrow angle radiation heat flux probes could be used. Modern labscale furnaces are equipped with heat sinks at the bottom of the furnace. These heat sinks are divided into several elements and the heat flux distribution can be measure simultaneously. For the control of the efficiency of radiant tubes, the flue gas outlet temperature has to be measured with a suction pyrometer or a simple thermocouple. For the measurement of the flue gas temperature, the measured temperatures have to be compensated for radiation loses of the thermocouples with the surrounding. Additionally the excess air ratio has to be controlled by $\mathrm{O}_{2}$ measurements within the flue gas of the radiant tube. The emissions of the radiant tubes can be measured with standard flue gas analyzing technologies for $\mathrm{NO}_{\mathrm{x}}$ and $\mathrm{CO}$.

In the case of radiant tube burners without air preheating and with recuperative air preheating technology the measurements should be carried out at steady-state conditions. In the case of the application of regenerative burners for radiant tubes no steady-state conditions will be achieved because of the switching between the regenerators. The unsteady-state conditions strongly depend on the switching time of the regenerators. For measurements in unsteady-state conditions, the time constant of the measuring instruments have to taken into account $[12,13]$. For more details about measurements at unsteady-state conditions, see Chapter 21 of this book.

\subsection{Comparative Performance Data Between Regenerative and Recuperative Radiant Tube Burners}

Within this chapter, measurements at a radiant tube with recuperative and regenerative burner technologies will be shown as an example of how measurements should be carried out. The measurements have been accomplished at the lab-scale furnace of KTH, Stockholm [6-8], which has been shown (Figure 24.7). A W-shape radiant tube, shown in Figure 24.9, was used in the experiments. The outer diameter of the tube was $0.195 \mathrm{~m}$ and its maximum thermal effect was $200 \mathrm{~kW}$.

The $74 \mathrm{~K}$-type thermocouples, placed in 41 locations, were mounted along the length of the tube, as shown in Figure 24.10. At least one thermocouple was mounted in each location on the right side of the tube. Points marked

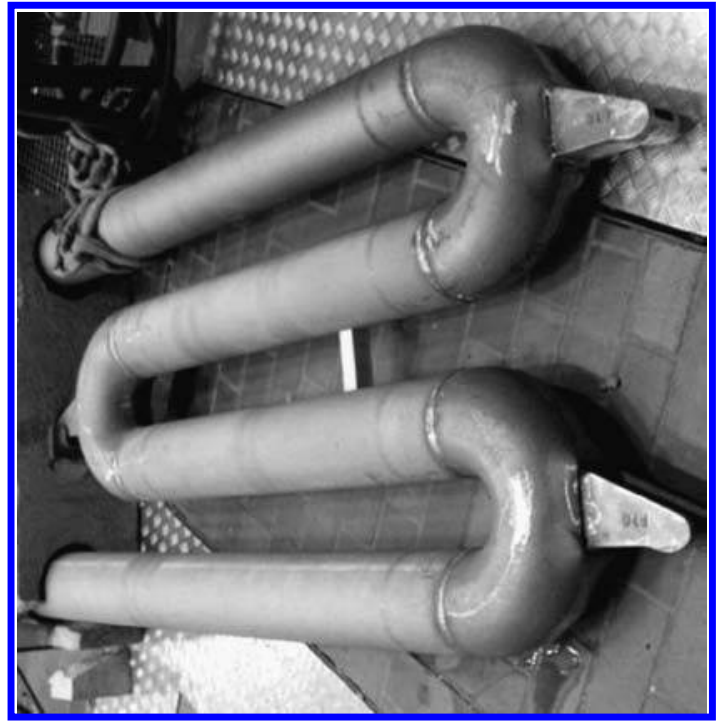

FIGURE 24.9

$\mathrm{W}$-shape radiant tube used for the experiments.

with 2s mean that there are two thermocouples, one is on the right side and the other is on the left side. Moreover, those locations that are close to burners are marked as $4 \mathrm{~s}$, meaning that there are four thermocouples on the left, right, top, and bottom. At elbows, there are three thermocouples, 3s, at the right, left, and at the surface that has the smaller radius. It was not possible to put the fourth thermocouple at elbows because the tube supports are located at that place. Tube temperature reference point (TRP), is located at a distance of $0.995 \mathrm{~m}$ from the beginning of the working part of the tube, Figure 24.10.

As a conventional system, the recuperative radiant type burning system, manufactured by Chugai Ro Kogyo Co. Ltd., with nominal firing capacity 175 kW, was used in order to compare with the (HRS) high-cycle regenerative system. The Figure 24.11 shows the measurement points in this system.

A HiTAC system, manufactured by Nippon Furnace Co., Ltd., (NFK) with nominal firing capacity $158 \mathrm{~kW}$, was used. This system is composed of a pair of burners, where one is working in firing mode and the other is working in regenerative mode at the same time. Modes were changed by a switching valve every 30 seconds. As a regenerator, a ceramic honeycomb was used. Figure 24.12 shows the measurement points in the system.

The fuel used for experiments was a typical LPG used by industry, composed of more than $98 \%$ propane, $0.9 \%$ ethane, and $0.8 \%$ butane with lower heating value equal to $93.2 \mathrm{MJ} / \mathrm{Nm}^{3}$.

The investigations using both burning systems were made at different operating conditions, such as reference point temperature, firing capacity, and air/fuel ratio. Table 24.1 shows the operating conditions of eight tests set together in order to compare the results 


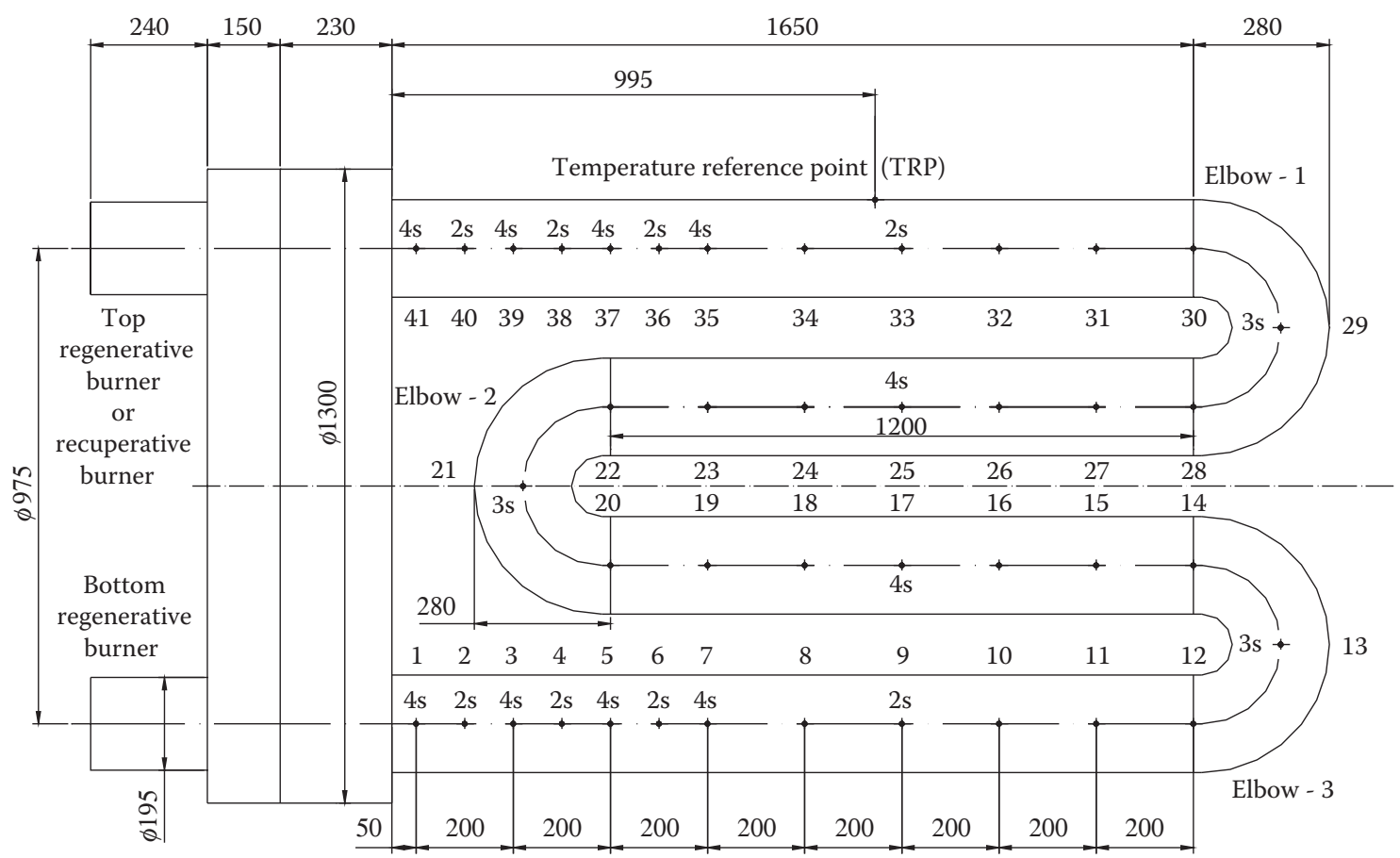

FIGURE 24.10

Schema of radiant tube and locations of temperature measurement points on the wall of the radiant tube.

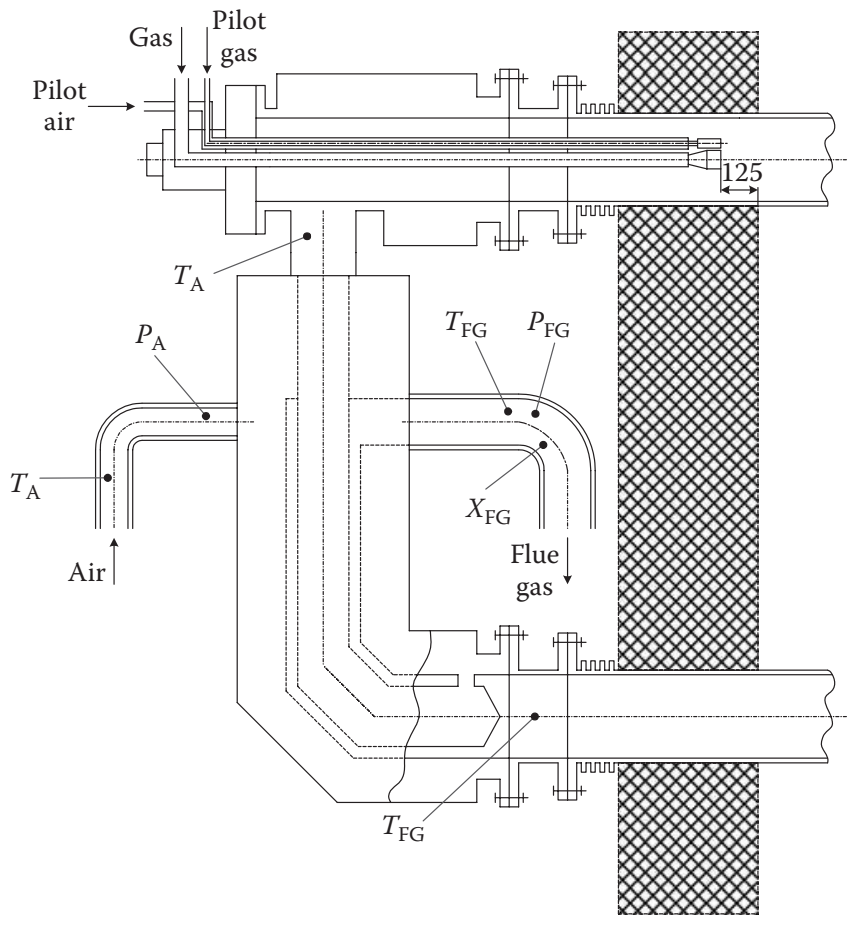

FIGURE 24.11

Recuperative system and location of measurement points.

afterward. Tests numbered from CRS-1 to CRS-4 refer to Conventional Recuperative System, while the others refer to High-cycle Regenerative System (HRS-1 to HRS-4). Comparisons were performed at four sets of reference point temperature (i.e., $840^{\circ} \mathrm{C}, 880^{\circ} \mathrm{C}, 950^{\circ} \mathrm{C}$,

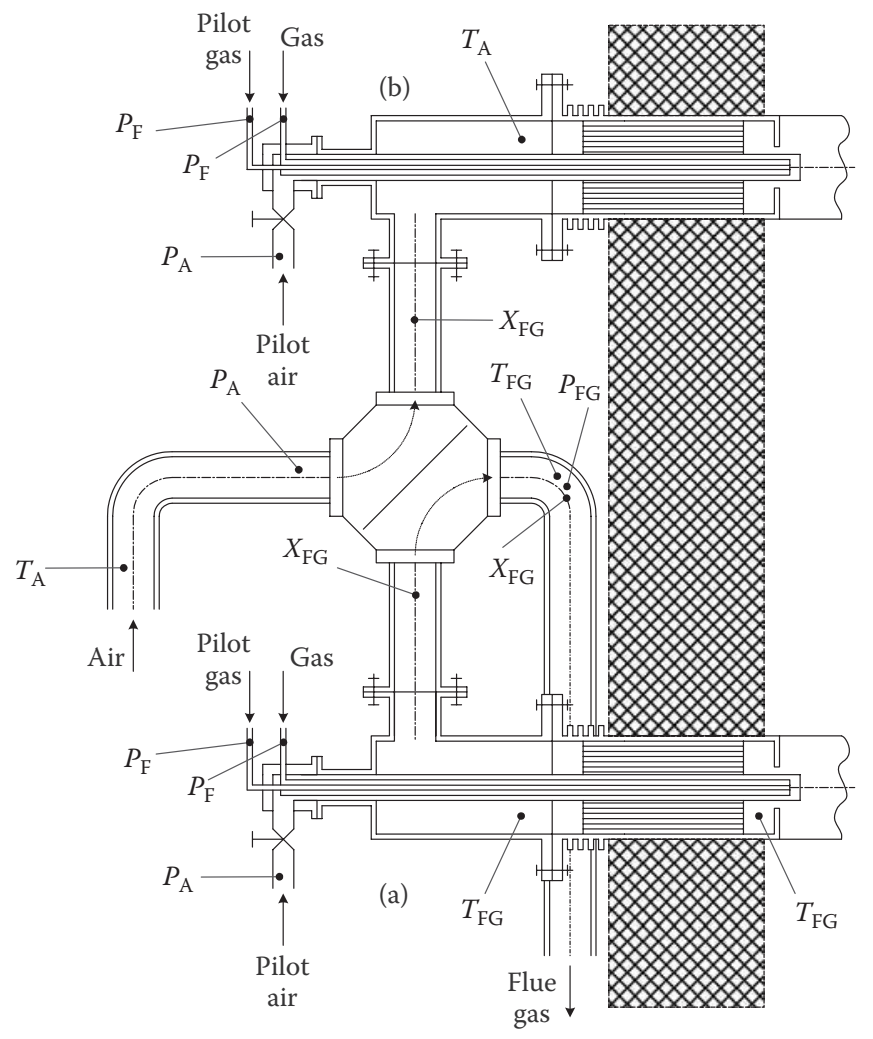

FIGURE 24.12

High-cycle regenerative system and location of measurement points. 
TABLE 24.1

Operating Conditions for the W-Type Radiant Tube

\begin{tabular}{|c|c|c|c|c|c|}
\hline No. & Test No. & $\begin{array}{c}\text { Burner } \\
\text { System Type }\end{array}$ & $T_{\mathrm{TRP}}$ & $V\left(Q_{\mathrm{F}}\right)$ & $\mathrm{O}_{2}$ \\
\hline - & - & - & ${ }^{\circ} \mathrm{C}$ & $\mathrm{Nm}^{3} / \mathrm{h}(\mathrm{kW})$ & $\%$ \\
\hline \multirow[t]{2}{*}{ I } & CRS-1 & recuperative & 840 & $3(78)$ & 3 \\
\hline & HRS-1 & regenerative & & & \\
\hline \multirow[t]{2}{*}{ II } & CRS-2 & recuperative & 880 & $5(129)$ & 3 \\
\hline & HRS-2 & regenerative & & & \\
\hline \multirow[t]{2}{*}{ III } & CRS-3 & recuperative & 950 & $5(129)$ & 3 \\
\hline & HRS-3 & regenerative & & & \\
\hline \multirow[t]{2}{*}{ IV } & CRS-4 & recuperative & 1000 & $6(155)$ & 3 \\
\hline & HRS-4 & regenerative & & & \\
\hline
\end{tabular}

and $1000^{\circ} \mathrm{C}$ ) and at three levels of firing capacity while the level of oxygen content was kept the same.

\subsubsection{Temperature Profiles}

The longitudinal temperature profiles were obtained using 41 thermocouples located on the right side of the radiant tube. Figure 24.13 shows these profiles for both, recuperative and regenerative, systems at different operating conditions. In the case of a recuperative system, the highest temperature occurred at a location very close to the TRP. At further distances, the temperature decreases along the tube length. The shape of profile is similar to typical shapes obtained when the conventional recuperative system is used. In the case of HRS there is at least one local peak at each end of the tube because of two burners. However, the rest of the temperature profile is almost steady and the temperature is level in about three meters length of the tube. Only at first comparison, the maximum temperature of the wall during tests is lower for HRS compared with CRS due to the difference of reference temperature point equaling $32^{\circ} \mathrm{C}$. When the difference of TRP between compared tests is in the order of a few Celsius degrees, the maximum temperature occurred on the profile of HRS. Although the maximum temperature is higher in the HRS case, the temperature difference, between maximum and minimum temperature of the radiant tube wall, is significantly lower, Table 24.2. This is an effect of the HiTAC features, where flame volume is large and temperature gradient in flames is lower. It is certain that uniformity of temperature distribution along the radiant tube is then better, and the longitudinal temperature profile can be treated as symmetrical.

These graphs show that the temperature level is much higher along the radiant tube in the case of HRS. This is a preliminary conclusion for a higher level of heat flux. Although the temperature difference increases with the decreased reference point temperature for both systems, this is not significant in the case of HRS.
TABLE $\mathbf{2 4 . 2}$

\begin{tabular}{lccccr}
\multicolumn{6}{c}{ Characteristic Temperatures on Longitudinal Profiles } \\
\hline No. & Test No. & $T_{\text {TRP }}$ & $T_{\text {MAX }}$ & $T_{\text {MIN }}$ & \multicolumn{1}{c}{$\Delta$ T } \\
\hline- & - & ${ }^{\circ} \mathbf{C}$ & ${ }^{\circ} \mathbf{C}$ & ${ }^{\circ} \mathbf{C}$ & ${ }^{\circ} \mathbf{C}$ \\
\hline I & CRS-1 & 847 & 842 & 633 & 209 \\
& HRS-1 & 815 & 824 & 750 & 74 \\
II & CRS-2 & 882 & 864 & 699 & 165 \\
& HRS-2 & 876 & 878 & 799 & 79 \\
III & CRS-3 & 949 & 931 & 805 & 126 \\
& HRS-3 & 949 & 960 & 895 & 65 \\
IV & CRS-4 & 1004 & 987 & 881 & 106 \\
& HRS-4 & 1007 & 1021 & 955 & 66 \\
\hline
\end{tabular}

It has to be noticed that although the profiles have been compared for the same maximum reference point temperature, the maximum temperature on the profiles, created for the right side of the tube, is not the same. It is due to the location of the TRP on the top of the tube. The real obtained maximum temperatures of the reference point are shown on graphs in Figure 24.13 and in Table 24.2. For all tests, the TRP point is situated on or very close to profile in the case of the HRS, while for the recuperative system this point usually is about $20^{\circ} \mathrm{C}$ higher than the maximum temperature of the right side profile. This is a result of nonuniform temperature distribution on the circumference, which will be explained further.

In the case of the HRS, both peak temperatures are placed closer to the ends of the radiant tube, than the location of TRP (which was equal to $0.995 \mathrm{~m}$ ). As a result the reference point temperature, which determines the life span of the tube, has to be moved to another place in the case of HRS. This temperature will be a few degrees higher on the top than on the right side, as will be described next. Temperatures around a cross section of the radiant tube at point 17 , located in the middle of the tube (Figure 24.10), are shown in Figure 24.14.

The graphs also show that for a cross-sectional profile, the temperature differences around the cross section of the tube are lower in the case of the HRS. In the case of the recuperative system, there is a noticeable (around $25^{\circ} \mathrm{C}$ ) temperature difference between the top and bottom sides of the tube. This difference is due to heating by the upper, hotter part and cooling by the lower, colder part of the tube. In the case of HRS, the temperature difference between both ends of the tube is negligible, because of cyclic work of the system and uniform, symmetrical, and longitudinal temperature profile. However, higher temperature at the bottom side, than that on the top, can be observed in contrast with the recuperative system. In this case it is because the considered measurement point is located closer to the lower part of the tube. This difference is negligible and in the result, the cross-sectional temperature profile is also more uniform. 
(a)

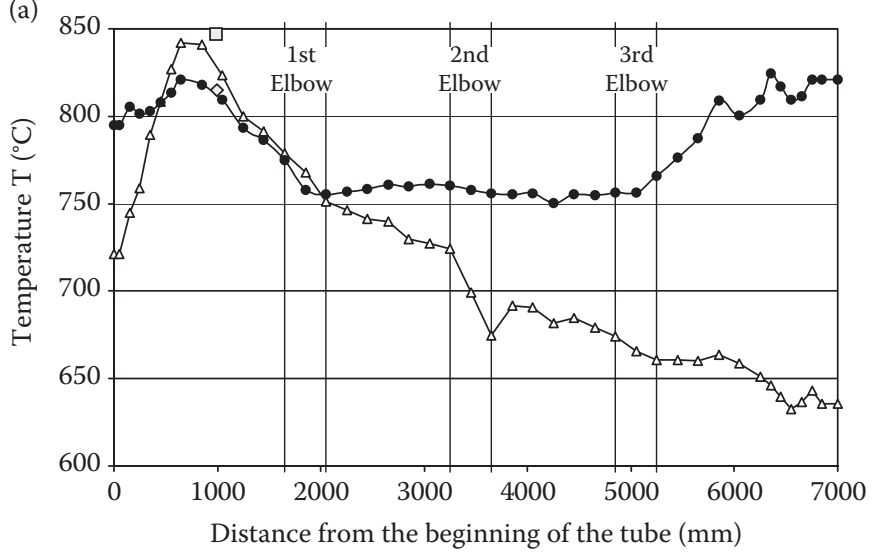

$\triangle$ CRS-1 $\square$ CRS-1-TRP

- HRS-1 $\diamond$ HRS-1-TRP

(c)

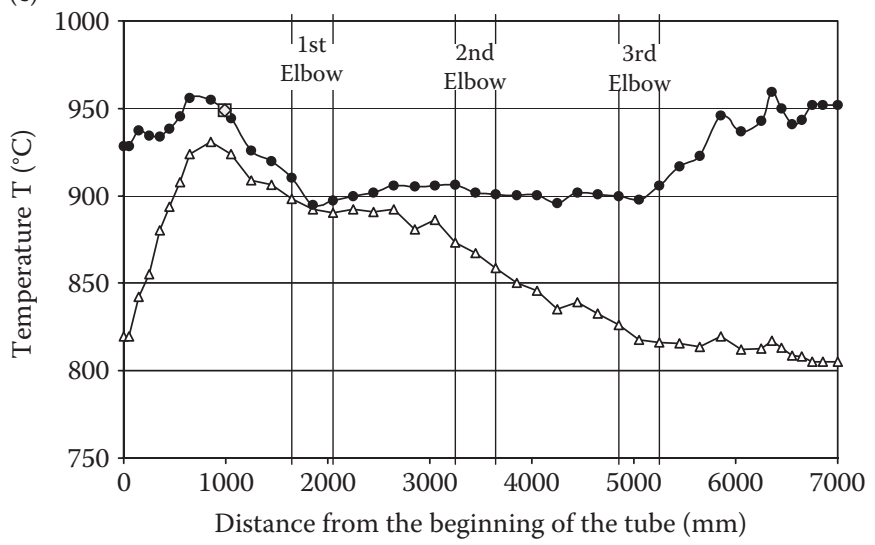

$\triangle-$ CRS-3 a CRS-3-TRP

$\rightarrow$ HRS-3 $\diamond$ HRS-3-TRP (b)

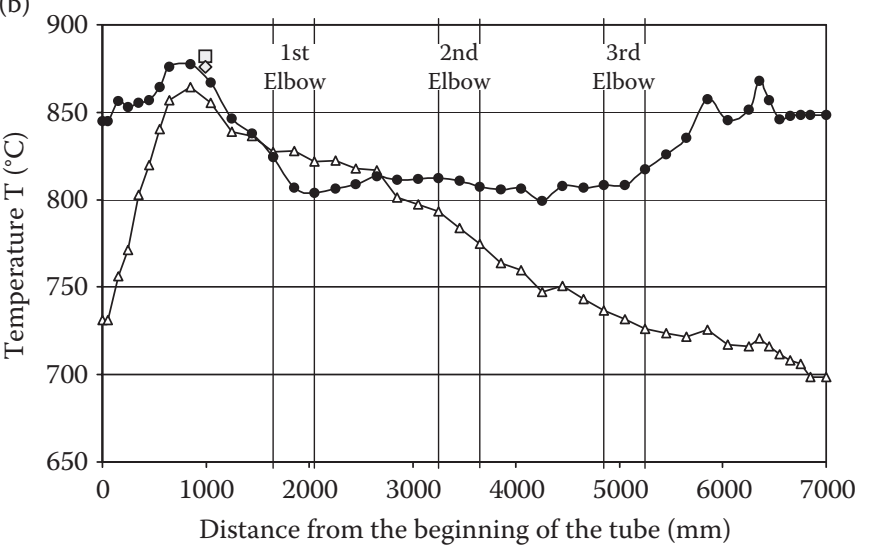

$\triangle$ CRS-2 CRS-2-TRP

- HRS-2 $\diamond$ HRS-2-TRP

(d)

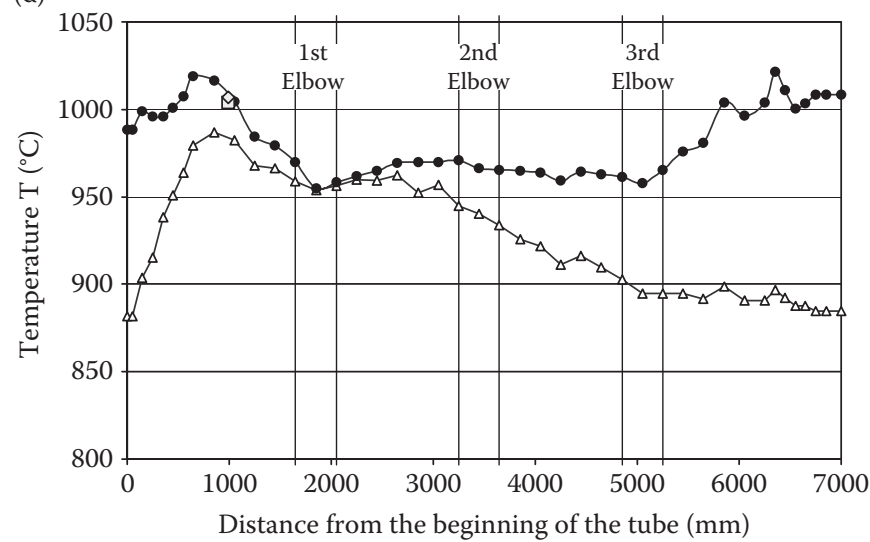

$\triangle$ CRS-4 $\square$ CRS-1-TRP

$\bullet$ HRS-4 $\diamond$ HRS-1-TRP

FIGURE 24.13

Longitudinal temperature profile of the radiant tube for recuperative and regenerative systems at different reference point temperature $T_{\mathrm{TRP}}$ : (a) $840^{\circ} \mathrm{C}$, (b) $880^{\circ} \mathrm{C}$, (c) $950^{\circ} \mathrm{C}$, and (d) $1000^{\circ} \mathrm{C}$.

\subsubsection{Effective Energy from the Radiant Tube}

In order to compare both systems, the effective energy from the radiant tube resulting from radiative heat flux, some assumptions were done due to different maximum temperatures on the right side longitudinal temperature profiles. Temperature profiles were displaced to have the same maximum temperature. This temperature was chosen as the average temperature, $T_{\mathrm{AV}, \mathrm{MAX}}$, from maximum values, $T_{\mathrm{MAX}}$, in each test. All temperature points were multiplied by factor $f$, Equation 24.1.

$$
f=\frac{T_{\mathrm{AV}, \mathrm{MAX}}}{T_{\mathrm{MAX}}} .
$$

As a result, the profile in the case of HRS was moved down a few degrees to lower the temperature region and the profile in the case of recuperative system was moved up a few degrees to the higher temperature region. In the first case it was opposite (Figure 24.15), because of a higher maximum right side temperature for CRS.

After these corrections, the radiative heat flux, $q$, was calculated, Equation 24.2.

$$
q=\frac{\sigma \times \varepsilon}{A} \sum A_{i} \times\left(T_{\mathrm{AV}, i}^{4}-T_{\mathrm{AV}, \mathrm{FR}}^{4}\right) .
$$

As 41 temperature measurement points were located with a different length between them, the temperature in every place after displacement $T_{\mathrm{AV}, i}$ was assumed to be the same in each surface area $A_{i}$. The difference between temperatures on the circumference was neglected, because of low value and because in practice the radiant tube emitted energy mainly from the right and left sides. Calculations were done assuming different 

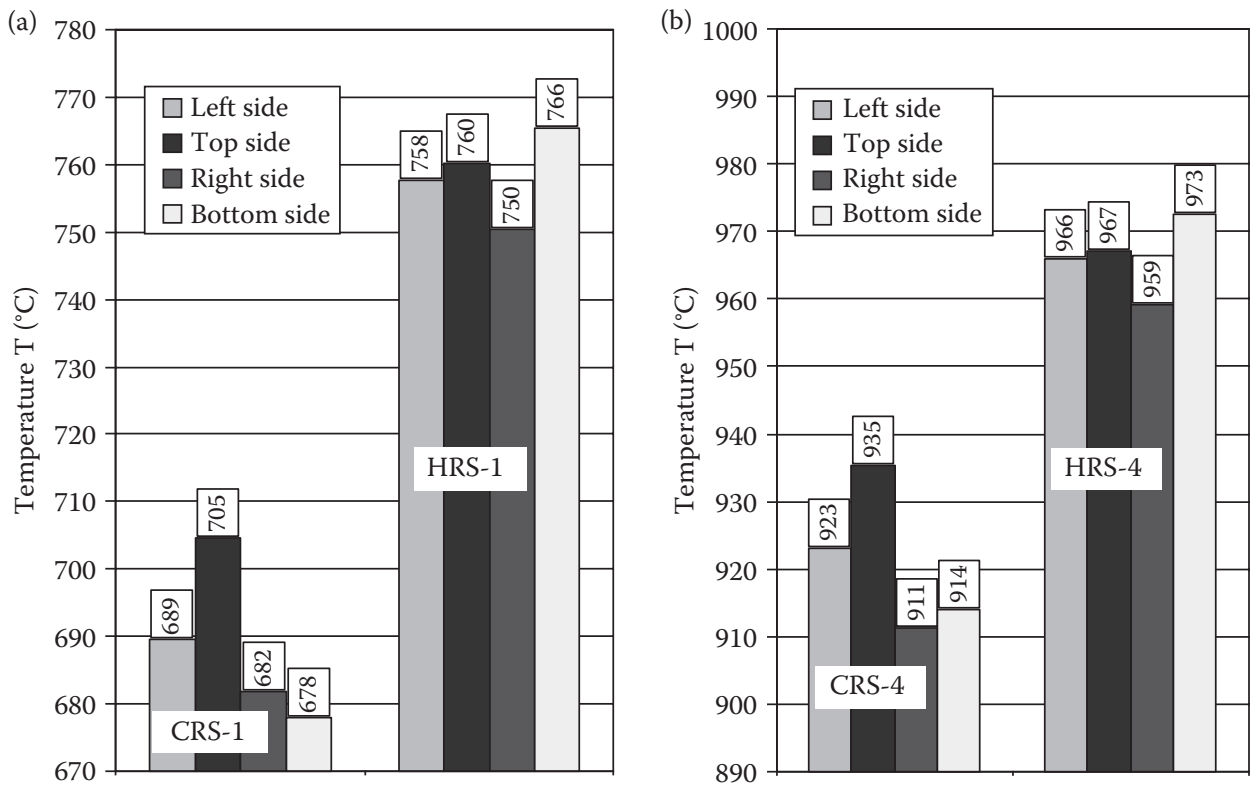

FIGURE 24.14

Cross-sectional temperature profile of the radiant tube at point 17: (a) for tests CRS-1 and HRS-1, (b) for tests CRS-4 and HRS-4.

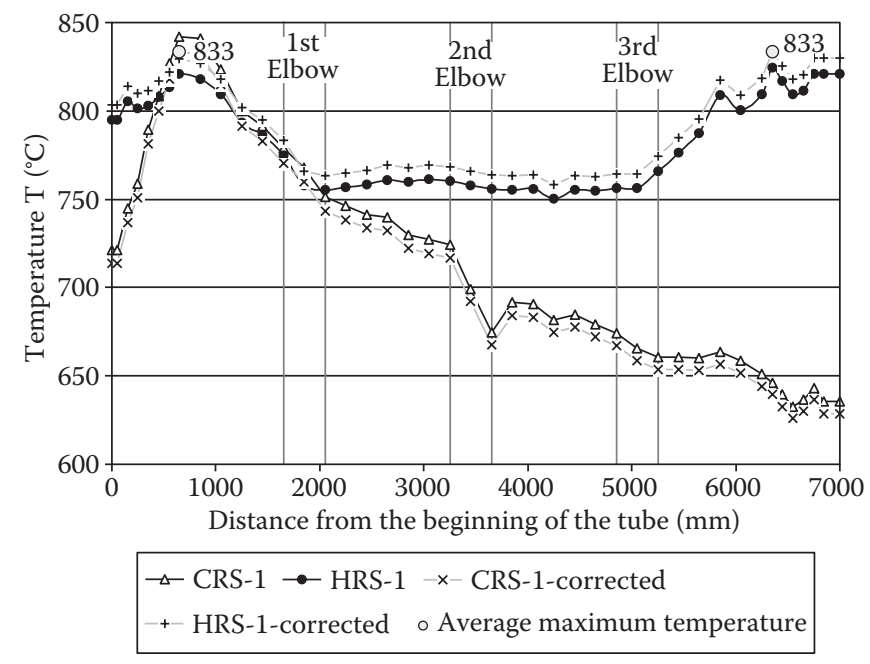

FIGURE 24.15

Longitudinal temperature profiles corrected to the same average maximum temperature.

average temperature inside the furnace (e.g., $250^{\circ} \mathrm{C}$, $500^{\circ} \mathrm{C}, 750^{\circ} \mathrm{C}$, and minimum temperature, $T_{\mathrm{AV}, \mathrm{MIN}}$, of the profiles, which always occurred in the case of a recuperative system). Finally, the heat flux ratio was calculated, Equation 24.3

$$
R=\frac{q_{\mathrm{HRS}}}{q_{\mathrm{CRS}}}
$$

The results of calculations (Table 24.3 and Figure 24.16) reveal that the radiative heat flux from the tube is always higher, when the HRS is used. This difference depends on operating conditions. Obviously it is dependent also on the average temperature in the furnace, $T_{\mathrm{AV}, \mathrm{F}}$, Figure 24.17. Graphs in this figure show the area of radiative heat flux at two average furnace temperatures. At lower temperatures, the area is mainly common for two systems and as a result, the heat flux ratio is not significantly high. However it can be clearly seen that at high temperatures of heat-treated material, the area in the case of HRS is about two times bigger than in the case of CRS, resulting in two times higher radiative heat flux.

When the temperature inside the furnace is low, the increase of the heat flux is about 6 and 38\% for high and low reference point temperatures, respectively. On the other hand, when the temperature inside the furnace is much higher, the increase of the heat flux goes over $100 \%$. In practice, it can be concluded that one of the advantages from the appliance of the HRS is that this technology has particularly huge benefits in the regions of furnace, where the temperature of heating treated material is high. The empty spaces in Table 24.3, first and second comparison, are because the minimum temperatures of the right side longitudinal temperature profile after correction were lower than $750^{\circ} \mathrm{C}$ and the heat flux calculation would not make sense.

From these results, one can conclude that for the same level of heat flux for both systems, the maximum temperature in the case of the HRS will be much lower than for a recuperative system, thereby 
TABLE 24.3

Radiative Heat Flux and Radiative Heat Flux Ratio

\begin{tabular}{|c|c|c|c|c|c|c|c|c|c|}
\hline \multirow[b]{2}{*}{ No. } & \multirow[b]{2}{*}{ Test No. } & \multicolumn{2}{|c|}{$T_{\mathrm{AV}, \mathrm{FR}}\left(250^{\circ} \mathrm{C}\right)$} & \multicolumn{2}{|c|}{$T_{\mathrm{AV}, \mathrm{FR}}\left(500^{\circ} \mathrm{C}\right)$} & \multicolumn{2}{|c|}{$T_{\mathrm{AV}, \mathrm{FR}}\left(750^{\circ} \mathrm{C}\right)$} & \multicolumn{2}{|c|}{$T_{\mathrm{AV}, \mathrm{FR}}\left(T_{\mathrm{AV}, \mathrm{MIN}}\right)^{*}$} \\
\hline & & $q$ & $R$ & $q$ & $R$ & $q$ & $R$ & $q$ & $R$ \\
\hline- & - & $\mathrm{kW} / \mathrm{m}^{2}$ & - & $\mathrm{kW} / \mathrm{m}^{2}$ & - & $\mathrm{kW} / \mathrm{m}^{2}$ & - & $\mathrm{kW} / \mathrm{m}^{2}$ & - \\
\hline \multirow[t]{2}{*}{$\bar{I}$} & CRS-1 & 31.8 & 1.36 & 21.6 & 1.54 & - & - & 10.8 & 2.07 \\
\hline & HRS-1 & 43.4 & & 33.2 & & - & & 22.4 & \\
\hline \multirow[t]{2}{*}{ II } & CRS-2 & 42.8 & 1.16 & 32.6 & 1.21 & - & - & 12.4 & 1.56 \\
\hline & HRS-2 & 49.7 & & 39.5 & & - & & 19.3 & \\
\hline \multirow[t]{2}{*}{ III } & CRS-3 & 60.1 & 1.12 & 49.8 & 1.15 & 23.0 & 1.32 & 11.4 & 1.64 \\
\hline & HRS-3 & 67.3 & & 57.1 & & 30.3 & & 18.7 & \\
\hline \multirow[t]{2}{*}{ IV } & CRS-4 & 77.6 & 1.06 & 67.4 & 1.07 & 40.6 & 1.11 & 12.4 & 1.37 \\
\hline & HRS-4 & 82.3 & & 72.0 & & 45.2 & & 17.0 & \\
\hline
\end{tabular}

*Values of $T_{\mathrm{AV}, \mathrm{MIN}}$ are shown in Figure 24.16.

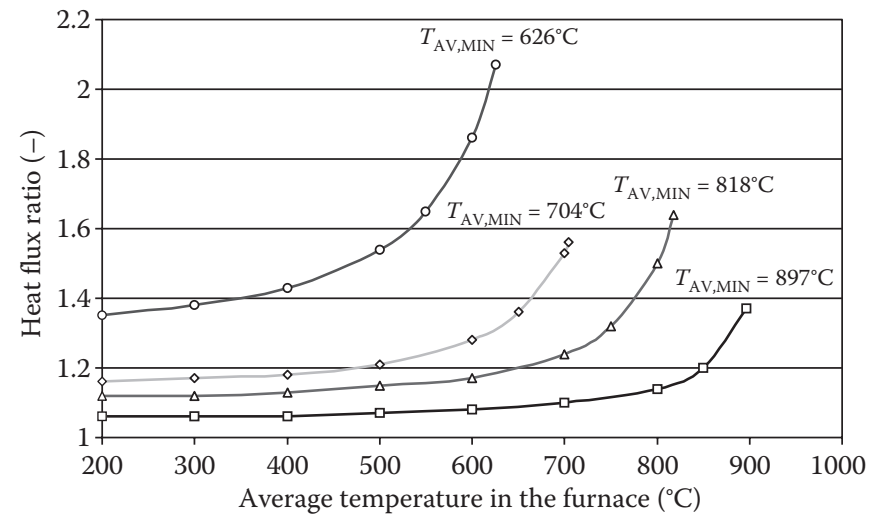

$\rightarrow-$ I (CRS-1 and HRS-1) $\diamond$ II (CRS-2 and HRS-2) $\triangle$ III (CRS-3 and HRS-3) $-\square-$ IV (CRS-4 and HRS-4)

\section{FIGURE 24.16}

Radiative heat flux ratio as a function of average furnace temperature.

influencing the life span of the radiant tube in a positive way.

\subsubsection{Energy Balance}

In order to do the energy balance for the whole system, the temperature of flue gas was measured as well as the temperature of the surface of burner units and pipes. Compensation of temperature measurement due to radiation to the pipe walls was made in order to find the real exhaust gas temperature. Calculating energy loss with flue gas, $Q_{\mathrm{FG}}$; estimating surface losses, $Q_{S}$; and having chemical energy of the fuel, $Q_{\mathrm{F}}$; and thermal energy of the air, $Q_{A}$; the efficiency of the system, $\eta$, was calculated, Equation 24.4

$$
\eta=\left(1-\frac{Q_{\mathrm{FG}}+Q_{\mathrm{S}}}{Q_{\mathrm{F}}+Q_{\mathrm{A}}}\right) \times 100 \%
$$
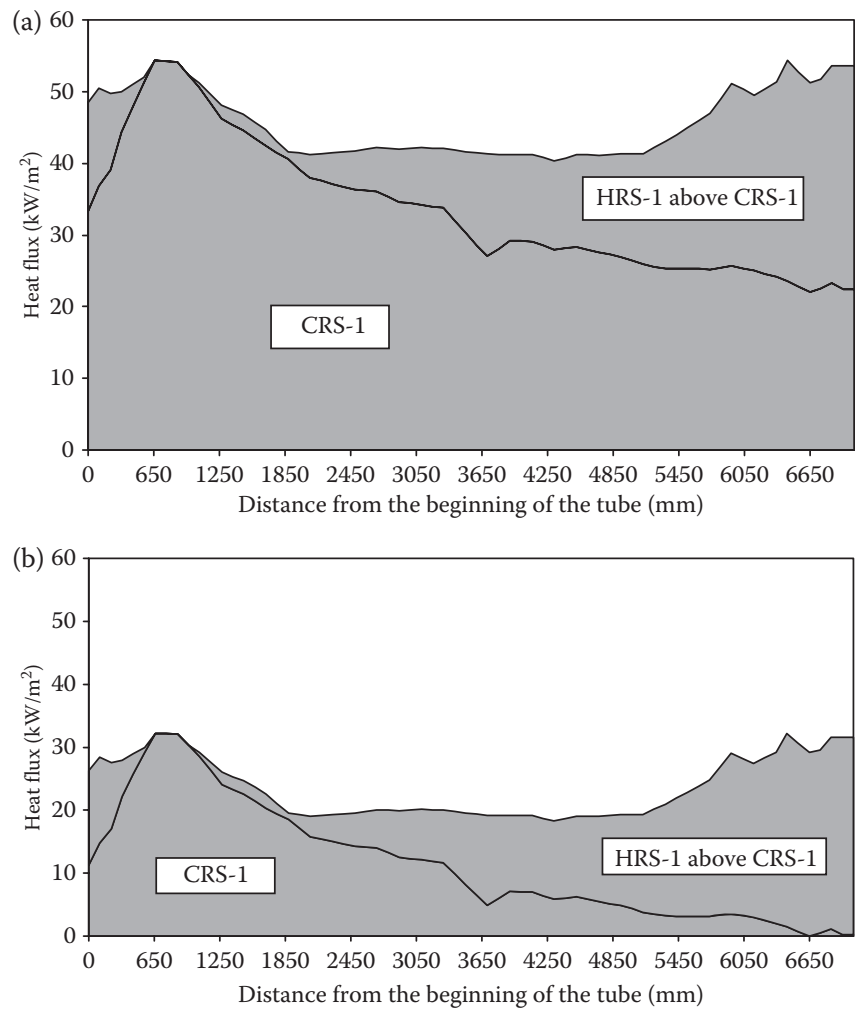

FIGURE 24.17

Radiative heat flux for CRS- 1 and HRS- 1 at different average temperatures in the furnace $T_{\mathrm{AV}, \mathrm{FR}}$ : (a) $250^{\circ} \mathrm{C}$, (b) $T_{\mathrm{AV}, \mathrm{MIN}}=626^{\circ} \mathrm{C}$.

The measurement and calculation results (Table 24.4) clearly reveal that efficiency of the whole system is higher in the case of a HRS. The difference is significantly big, up to $25 \%$. It becomes bigger in higher temperatures of the reference point. Higher efficiency for HRS is mainly due to a lower temperature of flue gases. The surface losses are also lower, because of a smaller surface area of burner units and pipes in comparison with a recuperative system. 
TABLE 24.4

Flue Gas Temperatures, Surface and Flue Gas Losses, and Efficiency of the System

\begin{tabular}{lcccccc}
\hline No. & Test No. & $\mathbf{T}_{\mathrm{FG}}$ & $\boldsymbol{Q}_{\mathrm{FG}}$ & $\mathbf{Q}_{\mathrm{S}}$ & $\eta$ & $\Delta \eta$ \\
\hline- & - & ${ }^{\circ} \mathbf{C}$ & $\mathbf{k W}$ & $\mathbf{k W}$ & $\mathbf{\%}$ & $\mathbf{\%}$ \\
\hline I & CRS-1 & 548 & 19.6 & 3.3 & 71.6 & 13.4 \\
& HRS-1 & 261 & 8.8 & 2.5 & 85.1 & \\
II & CRS-2 & 678 & 40.4 & 4.5 & 65.8 & 17.5 \\
& HRS-2 & 309 & 16.6 & 2.9 & 83.3 & \\
III & CRS-3 & 730 & 44.0 & 5.3 & 62.9 & 21.1 \\
& HRS-3 & 298 & 16.4 & 3.6 & 84.0 & \\
IV & CRS-4 & 815 & 58.9 & 6.1 & 58.6 & 24.2 \\
& HRS-4 & 325 & 21.4 & 4.1 & 82.8 & \\
\hline
\end{tabular}

\subsubsection{Emissions and Pressure Drop}

The pollutant emission measurements show that a HRS works with higher efficiency without the cost of higher $\mathrm{NO}$ emission. For example NO emission from the conventional recuperative system, calculated for $\lambda=1$, was equal to 179 ppm and 284 ppm in test CRS-1 and CRS-2, respectively, while it was more or less the same using HRS, 167 ppm and 316 ppm for HRS-1 and HRS-2 tests, respectively. No emission of $\mathrm{CO}$ was observed during normal operation for both systems.

The measurement of pressure difference across the systems revealed that the pressure drop due to HRS is more than 10 times higher than that when the conventional recuperative system is in operation. The pressure drop was 1.7 mbar and 2.8 mbar in cases CRS-3 and CRS-4, respectively, while it was 36 mbar and 30 mbar for HRS-3 and HRS-4, respectively.

\subsubsection{Conclusions from the Measurements with Different Burners}

Temperature profile of the wall of the radiant tube with the use of HRS is much more uniform in comparison with conventional recuperative system. This is applicable to both, the longitudinal and the cross-sectional, temperature profiles. As a result of the uniformity of temperature profile, the heat flux (energy released from the tube) is higher in the case of HRS for the same reference point temperature of the tube. The effective energy from the tube can be doubled in some cases, especially when the temperature of heat-treated material is high. It is much easier to control the temperature of the radiant tube equipped with HRS due to temperature distribution uniformity. The lifetime of the tube will be longer because the required level of heat flux can be achieved for a lower firing rate and with lower maximum temperature. System efficiency in the case of HRS is higher, up to $25 \%$ at the same reference point temperature. The above improvement of efficiency and effective energy

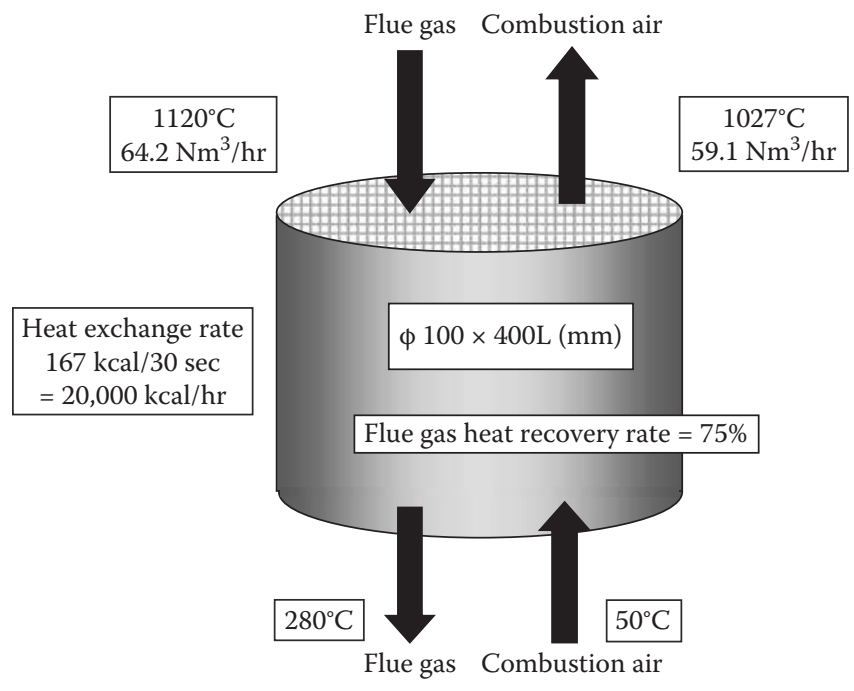

FIGURE 24.18

Example of heat balance calculation for a ceramic honeycomb regenerator.

emitted from the tube can be achieved using HRS without the expense of more $\mathrm{NO}_{\mathrm{x}}$ and $\mathrm{CO}$ emission.

\subsection{Thermal Performance of the Regenerator}

An example of heat balance calculation for a ceramic honeycomb regenerator [10,11] is shown in Figure 24.18. Combustion flue gas enters into the regenerator with $1120^{\circ} \mathrm{C}$ and leaves it with $280^{\circ} \mathrm{C}$, where air is preheated from $50^{\circ} \mathrm{C}$ to $1027^{\circ} \mathrm{C}$. In regenerative radiant tube burners the heat exchange rate of the regenerator is $23.3 \mathrm{~kW}$ and the flue gas heat recovery rate is $75 \%$. In regenerative radiant tubes, the capability of heat exchange rate per volume of the regenerator is very important in the compactness of the system as well as the low pressure loss nature of the regenerator as $100 \%$ of the flue gas leaves the radiant tube through the regenerator and bypassing a part of the flue gas is impossible. This is different from direct fired applications of regenerative burner systems where a part of the flue gas leaves the furnace via the stack without passing through the regenerator.

\subsection{Estimation of Mechanical Strength of the Radiant Tube}

In order to secure the mechanical strength of radiant tubes at a high temperature operation condition, a series 
of tests were executed by Japan Industrial Furnace Manufacturing Association (JIFMA) in a project organized by The Mechanical Social Systems Foundation (MSSF) under the financial support of Aggregate Corporation JKA in a test furnace measuring the temperature profile of the radiant tube with a regenerative and a conventional recuperative radiant tube burner $[10,11]$. By using these temperature data, numerical analysis for the thermal stress of the radiant tube for both burner systems were conducted.

\subsubsection{Conditions in Testing}

The inner dimensions of the test furnace are $1.0 \mathrm{~m}$ $(\mathrm{W}) \times 2.7 \mathrm{~m}(\mathrm{~L}) \times 2.3(\mathrm{H})$ and the radiant tube is equipped horizontally. The W-type radiant tube has a total length of $8055 \mathrm{~mm}$ and a diameter of 7 inches (outer diameter is $194 \mathrm{~mm}$ and inner diameter is $177 \mathrm{~mm}$ ). The material of the radiant tube is heat resistant cast steel (SCH24). The thermocouple positions is welded on the outside surface of the tube along the length and the tube circumference. The operation parameters in the tests are each $500-900^{\circ} \mathrm{C}$ for furnace temperature, $20-100 \%$ firing rate and 1.15 to 1.50 for excess air ratio.

\subsubsection{Temperature Profile along the Tube Length and the Tube Circumference}

Measured tube skin temperature profile along the tube length at furnace temperature of near $900^{\circ} \mathrm{C}$ with $100 \%$ load in a regenerative case is shown in Figure 24.19 and in a recuperative case is shown in Figure 24.20. These data show the regenerative case has a more uniform temperature profile along the tube length compared to the recuperative case.

These data show that the temperature difference is larger if the furnace temperature decreases. In the recuperative case the average temperature difference in all measured data is $112^{\circ} \mathrm{C}$ (standard deviation $24.5^{\circ} \mathrm{C}$ ). In the regenerative case it is $71^{\circ} \mathrm{C}$ (standard deviation 31.7), so that the value is lower by $41^{\circ} \mathrm{C}$ but the standard deviation is better by $7^{\circ} \mathrm{C}$ than the recuperative case.

The temperature profile along the tube circumference was measured in both regenerative and recuperative cases. The measured points are two positions along the tube length, one is $1213.5 \mathrm{~mm}$ and the other is $2013.5 \mathrm{~mm}$ from one end of the tube. In each position, four equal distance points along the tube circumference were measured. The average temperature differences and the standard deviation along the tube circumference for both regenerative and recuperative case are shown in Table 24.5. The results show that there are no significant average temperature differences along the tube circumference between a regenerative and recuperative burner system.

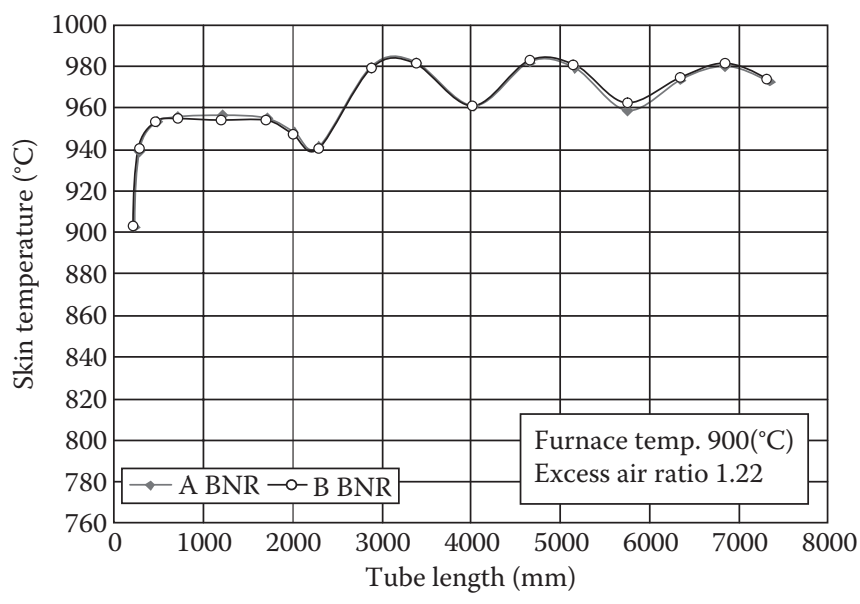

FIGURE 24.19

Tube skin temperature profile along the tube length in the regenerative burner. (Sudo, J., and Mochida, S., Internal paper on Radiant Tube Burner Testing, Yokohama, Japan: Nippon Furnace Co., Ltd., 2009. With permission.)

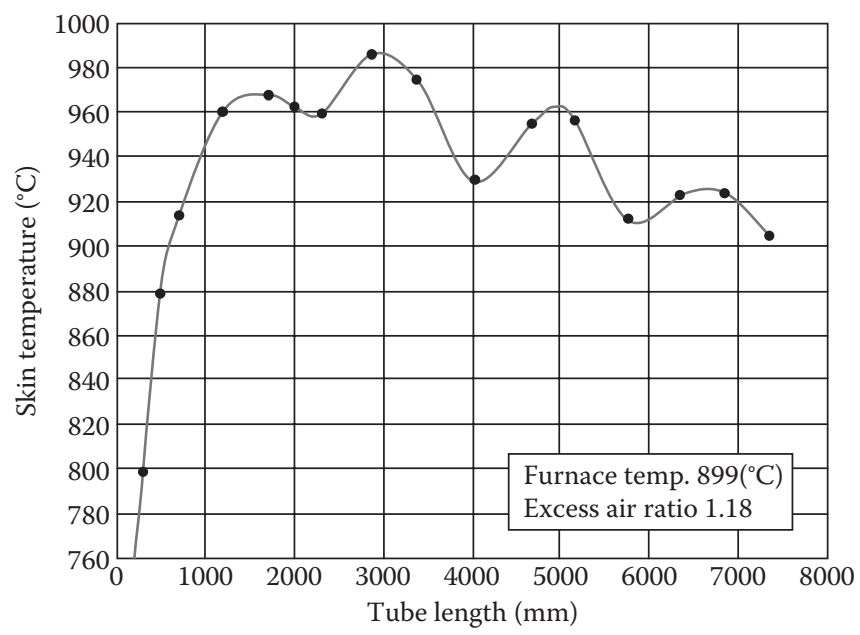

FIGURE 24.20

Tube skin temperature profile along the tube length in the recuperative burner. (Sudo, J., and Mochida, S., Internal paper on Radiant Tube Burner Testing, Yokohama, Japan: Nippon Furnace Co., Ltd., 2009. With permission.)

\subsubsection{Numerical Analysis of the Thermal Stress of the Radiant Tube}

With respect to the $\mathrm{W}$-type radiant tube used in the above noted comparative test, stress analysis was carried out in order to investigate the mechanical strength of the radiant tube. The method adopted is a Three Dimensional Elastic Stress Analysis using FEM ANSYS version 9, where the self-weight, measured temperature profile and assumed tube inside pressure at extraordinary combustion are considered. In the thermal stress analysis the measured tube surface temperature at 20 points, which seems to be timely, steady state was used as a smooth temperature curve over the measuring 
TABLE 24.5

Average Temperature Differences and the Standard Deviation along the Tube Circumference

\begin{tabular}{lcccc}
\hline Burner & $\begin{array}{c}\text { Temp. } \\
\text { Difference } \\
\text { at RT2 } \\
\text { Point }^{\circ} \mathbf{C}\end{array}$ & $\begin{array}{c}\text { Standard } \\
\text { Deviation } \\
{ }^{\circ} \mathbf{C}\end{array}$ & $\begin{array}{c}\text { Temp. } \\
\text { Difference } \\
\text { at RTA4 } \\
\text { Point }\end{array}{ }^{\circ} \mathbf{C}$ & $\begin{array}{c}\text { Standard } \\
\text { Deviation } \\
{ }^{\circ} \mathbf{C}\end{array}$ \\
\hline Regenerative & 32.38 & 7.59 & 22.09 & 7.33 \\
Recuperative & 34.0 & 15.5 & 19.75 & 9.6 \\
\hline
\end{tabular}

Source: Sudo, J., and Mochida, S., Internal paper on Radiant Tube Burner Testing, Yokohama, Japan: Nippon Furnace Co., Ltd., 2009. With permission.

TABLE 24.6

Calculation Results of the Thermal Stress on the Radiant Tube

\begin{tabular}{lcc}
\hline & \multicolumn{2}{c}{ Maximum Stress on the Tube (MPa) } \\
\cline { 2 - 3 } Burner & $\begin{array}{c}\text { Tube Inside } \\
\text { Pressure 0 MPa }\end{array}$ & $\begin{array}{c}\text { Tube Inside } \\
\text { Pressure 0.6 MPa }\end{array}$ \\
\hline Regenerative & 14.6 & 16.4 \\
Recuperative & 14.5 & 16.0 \\
\hline Source: & $\begin{array}{l}\text { Sudo, J., and Mochida, S., Internal paper on } \\
\text { Radiant Tube Burner }\end{array}$ & Testing, Yokohama, \\
Japan: Nippon Furnace Co., Ltd., 2009. With \\
permission.
\end{tabular}

points. The combustion conditions in the analysis are at $100 \%$ load firing and at target furnace temperature of $900^{\circ} \mathrm{C}$. This numerical analysis was done for both a regenerative and a recuperative burner.

The results are shown in Table 24.6 where the maximum stress on the tube between the regenerative and the recuperative burner is almost the same for both tube inside pressures of $0-0.6 \mathrm{MPa}$. These values are thought to be low enough than the creep rupture strength at $900^{\circ} \mathrm{C}$ with a long working time-about 10,000 hours - whereas average value of the creep rupture strength of the radiant tube material (KHR35H equivalent to $\mathrm{SCH} 24)$ used in the test is $31.0 \mathrm{MPa}$ (Min.26.9 MPa) at $900^{\circ} \mathrm{C}$ and 10,000 working hours. As a conclusion the possibility of a rising risk in terms of strength of the radiant tube is considered to be very low.

\subsection{Performance of Radiant Tubes at Industrial Applications}

The performance of radiant tube systems under production conditions in industrial applications can be estimated by measuring the flue gas outlet conditions like temperature, oxygen content, and emissions like $\mathrm{NO}_{\mathrm{x}}$. Together with measurements of total fuel consumption, conclusions concerning performance of heating systems can be drawn. In the case of retrofitting an existing furnace with more advanced technology measurements before and after retrofitting gives information about the differences related to efficiency and emissions. As discussed previously the efficiency of radiant tubes depend on the flue gas losses. In order to reduce the losses, systems with high heat recovery from flue gas should be implemented. The following two examples for retrofitting existing furnaces with regenerative radiant tubes will be discussed [10,11].

At a continuous galvanizing and annealing line furnace, 52 pairs of regenerative radiant tube burners were installed in a horizontal second heating zone of 140 tons/hr as shown in Figure 24.21. The 26 U-type radiant tubes, 7 inches in diameter are laid out over and under the strip line. The firing fuel is propane and the burner capacity is $140 \mathrm{~kW}$. The design furnace temperature is $950^{\circ} \mathrm{C}$ and the outlet material temperature is $750^{\circ} \mathrm{C}$. A major results waste heat recovery rate is $80.3 \%$ compared to $45.4 \%$ for the conventional burner before revamping. This leads to a fuel saving rate of $25.5 \%$. The $\mathrm{NO}_{\mathrm{x}}$ emission recorded was $118 \mathrm{pm}$ corrected to $11 \% \mathrm{O}_{2}$ at dry flue gas with external flue gas recirculation of $20 \%$. Some improvement of the outlet strip temperature uniformity is reported to have been achieved.

At a continuous roller hearth type annealing furnace 24 pairs of regenerative radiant tube burners were applied to the heating and soaking zone shown in Figure 24.22. The material to be heat treated is cast iron joints and design net capacity of the furnace is $1.67 \mathrm{ton} / \mathrm{hr}$. The total length of the furnace is $39 \mathrm{~m}$ and the maximum furnace temperature is $940^{\circ} \mathrm{C}$. The total length of the U-type radiant tube with 6 inches diameter is $4.3 \mathrm{~m}$. The radiant tubes are equipped horizontally in each upper and down side of the roller hearth. The fuel used is natural gas and the design burner firing rate is $81 \mathrm{~kW}$. As a result, the fuel consumption rate was $2,070 \mathrm{MJ} /$ ton, which is equivalent to about $52 \%$ reduction against a conventional burner type of the furnace. The $\mathrm{NO}_{\mathrm{x}}$ recorded was $120 \mathrm{ppm}$ corrected to $11 \% \mathrm{O}_{2}$ and dry flue gas.

\subsection{Summary and Conclusions}

Radiant tubes are used in industry for heat treatment application in which products are treated under a protective gas atmosphere within the heat treatment furnaces. There are different radiant tubes with different geometries, burners, air preheating technologies, and materials on the market. In order to increase the efficiency of radiant tubes, plug in recuperators, and recuperative or regenerative burners will be used at radiant tubes to 


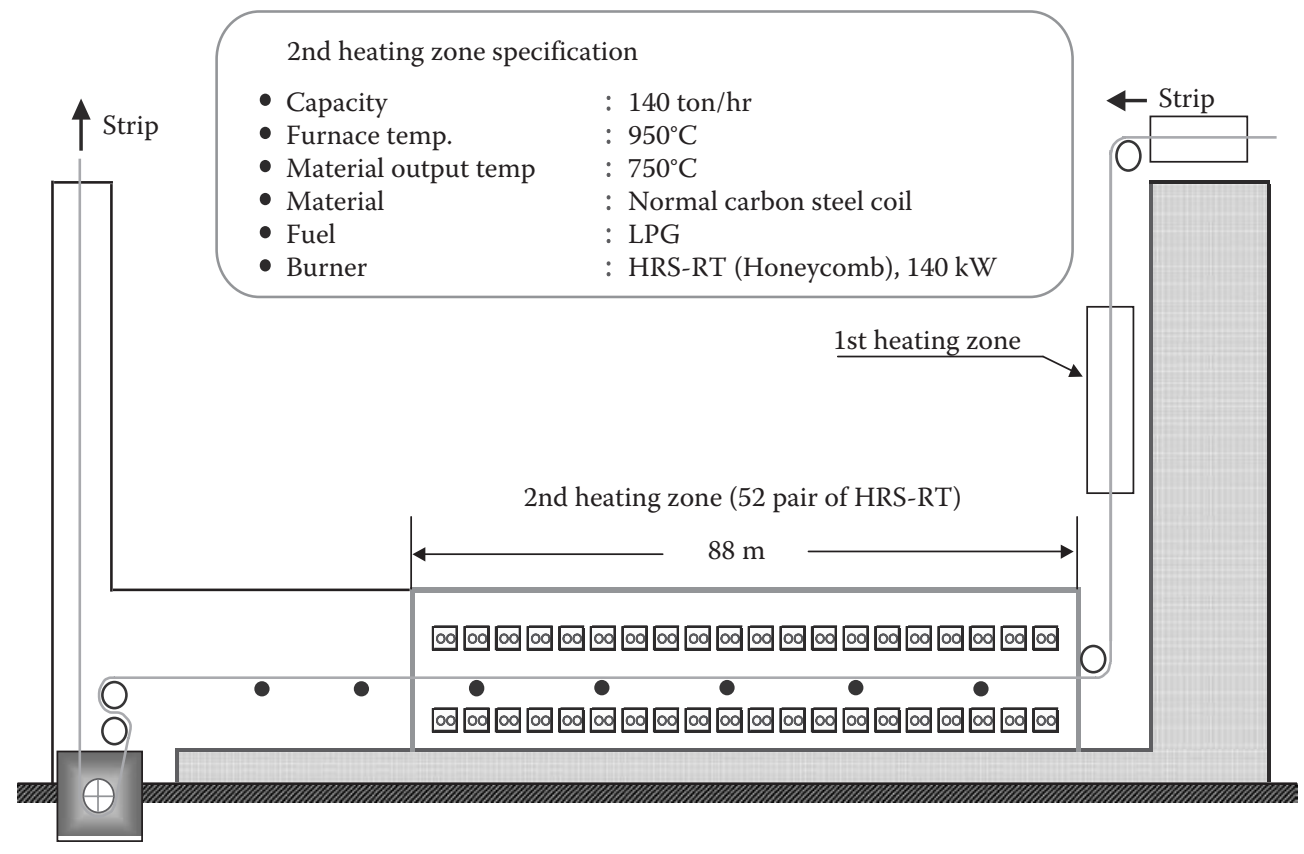

FIGURE 24.21

Schema of continuous galvanizing and annealing line furnace equipped with 52 pairs of radiant tube burners. (Sudo, J., and Mochida, S., Internal paper on Radiant Tube Burner Testing, Yokohama, Japan: Nippon Furnace Co., Ltd., 2009. With permission.)

\begin{tabular}{|ll|} 
Capacity & $: 1.67$ tons $/ \mathrm{hr}$ \\
Heating material & $: J o i n t s$ \\
Furnace temperature & $: 940^{\circ} \mathrm{C}$ (Max.) \\
Fuel & $:$ Natural gas \\
RT & $: 6$ inch, U type \\
Draft & $:$ Pull \\
Firing rate per burner & $: 81 \mathrm{~kW}$ \\
\hline
\end{tabular}

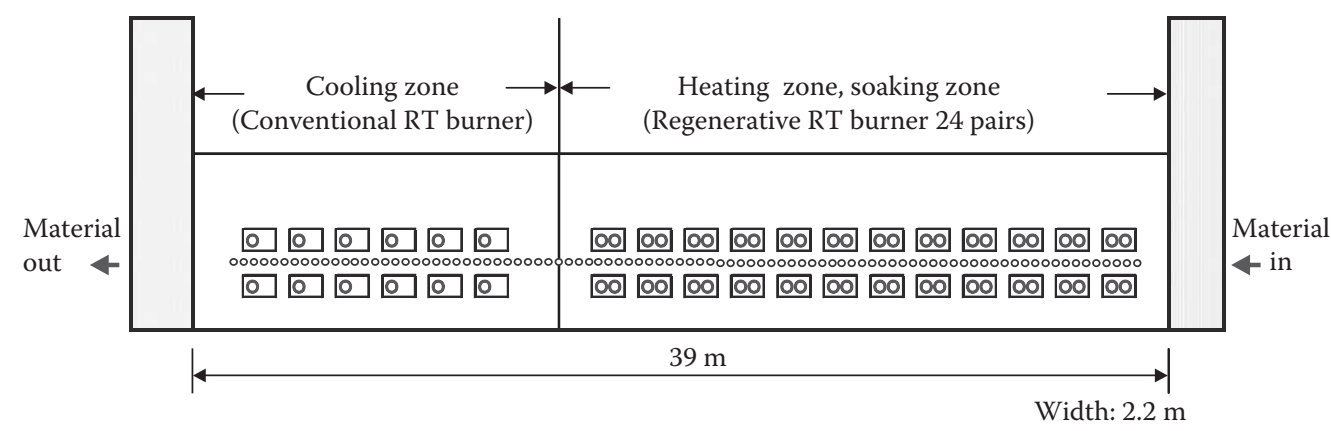

FIGURE 24.22

Schematic drawing of a continuous roller hearth type annealing furnace equipped with 24 pairs of regenerative radiant tube burner. (Sudo, J., and Mochida, S., Internal paper on Radiant Tube Burner Testing, Yokohama, Japan: Nippon Furnace Co., Ltd., 2009. With permission.)

use the energy from flue gas for preheating the combustion air. The most important quality characteristics of radiant tubes are the maximum heat flux from the tubes to the process/product, the temperature uniformity at the surface of the radiant tubes, and the heat flux uniformity versus the length of the radiant tubes. Another very important quality characteristic is the combustion efficiency (fuel efficiency) of radiant tubes. The efficiency strongly depends on the flue gas outlet temperature of radiant tube systems. High efficiencies with less flue gas losses results in lower fuel consumptions and lead to a reduction of the $\mathrm{CO}_{2}$ emission per ton of product. Hazardous emissions like $\mathrm{NO}_{x}$, and unburned gases like CO should also be as low as possible. In order to test radiant tubes the systems have to be implemented in lab-scale furnaces in which one can achieve similar conditions like in industrial applications concerning process temperature, surface temperature of the radiant 
tubes, and heat flux. The thermal input of industrial scale radiant tubes is in general less than $300 \mathrm{~kW}$ so that it is possible to test industrial scale radiant tubes at labscale furnaces. For the experimental investigations it is important to have a defined condition within the labscale furnace in order to allow a transfer of the achieved result to the industrial furnace. In the case of a comparison of different burners and heat recovery technologies it is important to have the same boundary conditions for the experiments in order to allow an exact comparison of the different tested technologies. With measured temperature profiles a thermal stress analysis of the radiant tube is possible on the basis of numerical simulation. Tests in industrial applications are also possible but not as easy without any disturbances of the production process. On an industrial applications general information about the performance of the radiant tubes, the whole furnace can be collected without disturbance of the process by measuring the flue gas outlet conditions of the radiant tubes and the fuel consumption of the furnace.

\subsection{Nomenclature}

$\begin{array}{ll}A & =\text { surface area, } \mathrm{m}^{2} \\ \mathrm{CRS} & =\text { conventional recuperative system } \\ \mathrm{HRS} & =\text { high-cycle regenerative system } \\ f & =\text { correction factor } \\ Q & =\text { energy rate, } \mathrm{W} \\ q & =\text { heat flux, } \mathrm{W} / \mathrm{m}^{2} \\ R & =\text { ratio } \\ \mathrm{RT} & =\text { radiant tube } \\ T & =\text { temperature, }{ }^{\circ} \mathrm{C} \\ \mathrm{TRP} & =\text { temperature reference point } \\ V & =\text { volumetric flow rate, } \mathrm{Nm}^{3} / \mathrm{h} \\ \Delta & =\text { difference } \\ \varepsilon & =\text { emissivity } \\ \eta & =\text { efficiency } \\ \sigma & =\text { Stefan-Boltzmann constant }\end{array}$

\section{Subscripts}

$\begin{aligned} \mathrm{MIN} & =\text { minimum } \\ \mathrm{MAX} & =\text { maximum } \\ \mathrm{A} & =\text { air } \\ \mathrm{AV} & =\text { average } \\ \mathrm{F} & =\text { fuel } \\ \mathrm{FG} & =\text { flue gas } \\ \mathrm{FR} & =\text { furnace } \\ \mathrm{S} & =\text { surface }\end{aligned}$

\section{References}

1. Wünning, J. G., and Milani, A. Handbook of Burner Technology for Industriol Furnace. Essen, Germany: Vulkan Verlag, 2009.

2. Milani, A., and Wünning, J. G. "Radiant Tube Technology for Strip Line Furnaces." IFRF Combustion Journal, Article No 200405, ISSN 1562-479-X, November 2004.

3. Wünning, J. G. "Ceramic Radiant Tubes Extend Performance Limits." Industrial Heating, March 2002.

4. Wünning, J. G. "Retrofitting Radiant Tube-Heated Furnaces." Industrial Heating, June 2003.

5. Wünning, J. G. "Self Regenerative Burner for SingleEnded, P and Double-P Radiant Tubes." Industrial Heating, June 2007.

6. Rafidi, N., and Blasiak, W. "Experimental Study: Thermal Performance of Ceramic Regenerative Heat Exchangers Used in HiTAC Regenerative Burning Systems." Proceedings of the 25th Topic Oriented Technical Meeting of the IFRF, Stockholm, Sweden, 2003.

7. Szewczyk, D., Blasiak, W., Jewartowski, M., and Rafidi, N. "Increase of the Effective Energy from the Radiant Tube Equipped with High-Cycle Regenerative System (HRS) in Comparison with Conventional Recuperative System." Proceedings of the 25th Topic Oriented Technical Meeting of the IFRF, Stockholm, Sweden, 2003.

8. Rafidi, N, Blasiak, W., Jewartowski, M., and Szewczyk, D. "Increase of the Effective Energy from the Radiant Tube Equipped with Regenerative System in Comparison with Conventional Recuperative System." IFRF Combustion Journal, Article No 200503, ISSN 1562479X, 2005.

9. Canmet Energy Technology Centre. "Brochure: Test Bed for New Combustion Technologies." 2008. http:/ / canmetenergy.nrcan.gc.ca / fichier.php/codectec/ En/2008-40/Test +Bed+for+Combustion.pdf (accessed November 5, 2008).

10. Sudo, J., and Mochida, S. Internal Paper on Radiant Tube Burner Testing. Yokohama, Japan: Nippon Furnace Co., Ltd., 2009.

11. Japan Industrial Furnace Manufacturing Association (JIFMA)/The Mechanical Social Systems Foundation (MSSF). Investigation Report for Safety Improvement in Heat Treatment Industries, 2007.

12. Szewczyk, D., Mörtberg, M., Rafidi, N., Dobski, T., and Blasiak, W. "Measurements of Temperature and Heat Flux in HiTAC Flame for Unsteady State Conditions." 5th International Symposium on High Temperature Air Combustion, Yokohama, Japan, 2002.

13. Krishnamurty, N., Szewczyk, D., Blasiak, W., Manuel, S., and Hortawed, T. "Measurements of Temperature Using Fine Wire Compensated Thermocouple in Furnace Equipped with High-Cycle Regenerative System." 25th Topic Oriented Technical Meeting of the IFRF, Stockholm, Sweden, 2003. 